\title{
La asamblea, el teatro y el pensamiento de la decisión en la democracia ateniense
}

Assembly, Theater, and the Thinking of the Decision in the Athenian Democracy

\author{
Julián GALLEGO \\ Universidad de Buenos Aires \\ julianalejandrogallego@hotmail.com
}

\begin{abstract}
RESUMEN: El artículo analiza el funcionamiento de la asamblea ateniense durante el siglo $\mathrm{v}$ a. C., tomando en cuenta los efectos del uso del discurso persuasivo, así como el proceso de pensamiento que se desarrollaba en ese espacio colectivo. En función de esto, se consideran las formas de participación del público, comparándolas con la actuación de la audiencia en el teatro. Se plantea asimismo la hipótesis de una homología entre asamblea y teatro. Finalmente se hace hincapié en el rol de lo emocional en la toma de decisiones.
\end{abstract}

ABSTRACT: The article analyzes the functioning of the Athenian assembly during the fifth century $\mathrm{BC}$, taking into account the effects of the use of persuasive speech and the thinking process that was developed in this collective space. In this light, the ways of public participation are considered comparing them with the audience performance in the theater. The hypothesis of a homology between assembly and theater is also proposed. Finally, it is emphasized the role of the emotional matter in the decision-making process.

Palabras Clave: Atenas; democracia; asamblea; teatro; espectador; decisión; coraje. Keywords: Athens; Democracy; Assembly; Theater; Spectator; Decision; Courage.

RECIBIDO: 20 de septiembre de 2015 - ACEPTADO: 25 de abril de 2016.

DOI: 10.19130/iifl.nt.2016.33.2.707

En este trabajo nos proponemos abordar el problema de la acción política en la Atenas democrática, considerando la actividad deliberativa de la asamblea como una práctica de pensamiento y confrontando este registro discursivo con la habitual significación que la idea de teoría ha adquirido en nuestra cultura. Esto conlleva un supuesto que conviene explicitar de entrada: mientras que la reflexión contemplativa resulta ser una mirada externa a las prácticas mismas y por consiguiente pasiva respecto de lo que opera en acto, en cambio, el pensamiento activo produce su sentido en una articulación inmanente con el sujeto de una acción que es en sí misma pensamiento y en ello consiste su propia trayectoria práctica como agente. Desde este punto de vista, la pregunta básica es la siguiente: ¿el pueblo ateniense era un agente activo o pasivo cuando 
se debatían y tomaban las decisiones? Aquí sostendremos el carácter performativo del uso de la palabra ${ }^{1}$ en el procedimiento asambleario como el modo en que el discurso político hace ser en acto un mundo que, en sí mismo, se instituye como un asunto de logos y de polis.

Vamos a desarrollar nuestro argumento a través de un recorrido que nos llevará a establecer el rol que se plantea para quienes aparecen en posición de espectadores, indagando si en el contexto de la democracia ateniense esto comportaba el mismo carácter pasivo que Pitágoras les había atribuido al trazar un paralelismo con los filósofos, según la propuesta de Hannah Arendt. A partir de esto, trataremos de delimitar el campo del término $\theta \varepsilon \omega \varrho i ́ \alpha$ en relación con el problema de la observación conforme a dos maneras de concebir el uso de la palabra: la representación que hace ver y la intervención que hace ser. Considerando la contraposición que específicamente parece conformarse en un pasaje de un discurso que Tucídides ponía en boca de Cleón, entre los ciudadanos atenienses considerados como espectadores (III, 38, 4: $\theta \varepsilon \alpha \tau \alpha i ́)$ y como pensadores (III, 40, 5: $\dot{\varepsilon} v \theta v \mu \eta \theta \dot{\varepsilon} v \tau \varepsilon \varsigma$ ), buscaremos discernir qué figura subjetiva se instituye en el proceso práctico de la asamblea y cuál es su capacidad singular con respecto al uso de la palabra como productora de sentido. Esto nos llevará a discutir el tipo de relación de los espectadores con el espectáculo teatral, el carácter de la actividad que realizaban y su posible homología con el desempeño de los ciudadanos en la asamblea. Con la finalidad de demostrar lo que asumimos como un rol activo de los atenienses como espectadores en el teatro y como ciudadanos en la asamblea, examinaremos ambos desempeños a partir de la idea de audacia o coraje ( $\tau$ ó $\lambda \mu \alpha)$ con la cual se los cualifica en Tucídides (II, $40,3)$ y en Platón ( $L g ., 700$ e), respectivamente, cuya consecuencia es la pérdida del miedo reverencial a la autoridad. El análisis del verbo غ̇v $\theta v \mu o v ́ \mu \varepsilon \theta \alpha$ en el contexto de la deliberación asamblearia nos permitirá indagar la dimensión emocional de la palabra política ligada al $\theta v \mu o ́ s$, como otra forma de coraje, y al uso persuasivo del entimema. Por último, exploraremos las subversiones que se producen con respecto al rol

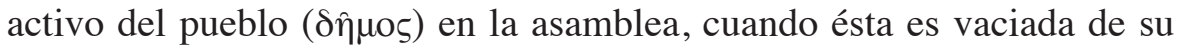
poder efectivo a raíz del golpe oligárquico de 411 a. C., situación en la

${ }^{1}$ Cf. Austin 1962, passim, y esp. pp. 94-131 (Lectures VIII, IX y X); Longworth 2015, § 2.3 Speech Acts and Truth. 


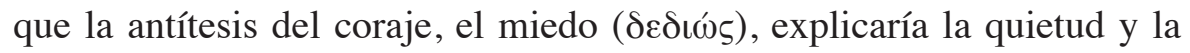
incapacidad del pueblo para actuar.

En el apartado dedicado a Pitágoras en las Vidas de los filósofos ilustres (VIII, 8), Diógenes Laercio retomaba una sentencia transmitida por Sosícrates en sus Sucesiones, según la cual el filósofo de Samos comparaba la posición en la que se hallaban los espectadores de un festival con la función que desempeñaban los filósofos en la vida: ${ }^{2}$

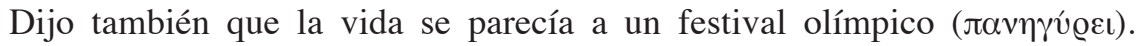
Porque, así como a éste acuden los unos a competir en los juegos, otros por motivos de negocios y los más dignos como espectadores ( $\theta \varepsilon \alpha \tau \alpha i ́)$, así en la vida unos son de naturaleza servil, otros son cazadores de fama y fortuna y los otros filósofos que van en pos de la verdad $(\dot{\alpha} \lambda \eta \theta \varepsilon i ́ \alpha \varsigma){ }^{3}$

Partiendo de este texto en el que Pitágoras definía el rol del filósofo y se asumía como tal, Hannah Arendt daba cuenta de una separación entre dos órdenes de la vida sobre los que la autora ha insistido en más de una ocasión: la vida activa y la vida contemplativa. ${ }^{4}$ En este sentido, el

${ }^{2}$ La transmisión de esta idea, según la cual Pitágoras habría sido el primero en usar el término "filósofo" para referirse a la actividad contemplativa ligada a la búsqueda de la verdad, se puede rastrear en otros autores que consignan prácticamente la misma información que Diógenes Laercio, como Jámblico, que usa los términos $\theta \varepsilon ́ \alpha$ y $\theta \varepsilon \omega \varrho i ́ \alpha$ para dar cuenta de las actividades respectivas de quienes se dirigen a los festivales para observar y de quienes se dedican a la filosofía (Iamb., VP., XII, 58), o Cicerón, que recurre a un pasaje de una obra perdida de Heráclides Póntico y señala el papel de quienes van como espectadores a los festivales con el término visendi mientras que la función del filósofo se delimita como contemplatio (Cic., Tusc., V, 3, 8-9). Hay otra versión en la Vida de Apolonio de Tiana de Filóstrato, con un contenido semejante, pero en la que la aserción se atribuye al pitagórico Apolonio no a Pitágoras (Philostr., VA, VII, 18). Cf. Rusten 1985, p. 15; García Romero 2013, pp. 148-149.

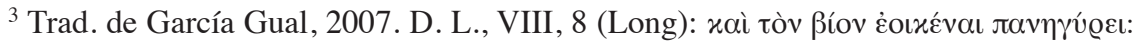

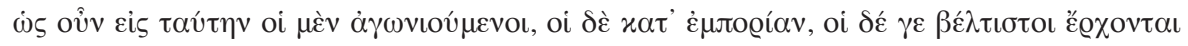

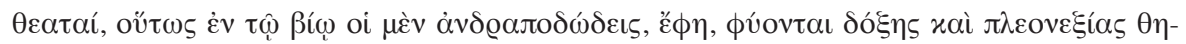

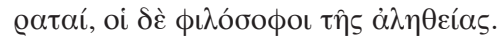

${ }^{4}$ Cf. Arendt 1958, passim, sobre la distinción fundamental entre vita activa y vita

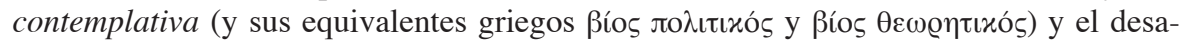


espectador y el filósofo, haciendo ahora caso omiso de las importantes diferencias entre ambos, aparecen en una posición análoga en cuanto a la capacidad de ver la verdad de lo que transcurre ante su mirada pero sin posibilidad de intervenir en el proceso:

From the Greek word for spectators, theatai, the later philosophical term "theory" was derived, and the word "theoretical" until a few hundred years ago meant "contemplating", looking upon something from the outside, from a position implying a view that is hidden from those who take part in the spectacle and actualize it. The inference to be drawn from this early distinction between doing and understanding is obvious: as a spectator you may understand the "truth" of what the spectacle is about; but the price you have to pay is withdrawal from participating in it. ${ }^{5}$

¿Es que tratar con la verdad supone necesariamente retirarse para poder contemplarla? ¿Implica el pensamiento una observación que es forzosamente teórica en la medida en que interpreta o hace inteligible el mundo, y en cierto modo lo ordena al mismo tiempo que lo observa, pero a condición de situarse en una posición no participativa con respecto al mismo? Esto parece ser lo que forzosamente debe asumirse a partir de las conclusiones de Arendt, así como frente a lecturas como la de Diógenes Laercio en el siglo III d. C. Pero la articulación establecida entre el rol del $\theta \varepsilon \alpha \tau$ ís y la idea de teoría convoca otro problema, que es el de los comienzos de un tipo de actividad que no sería necesariamente el que llevaría a cabo el espectador teatral, aun cuando también implicara una forma de observación. Nos referimos a la tarea que realizaba

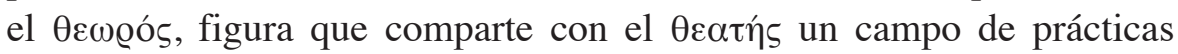
ligado a la observación y el espectáculo, aunque no estén enteramente probadas las vinculaciones en el terreno etimológico. ${ }^{6}$ De todas maneras,

rrollo de esta contraposición en la cultura occidental. Recientemente, el problema de la vida contemplativa desde la época helenística hasta la Antigüedad tardía ha sido analizado en un libro completo dedicado a esta cuestión: Bénatouïl y Bonazzi (eds.) 2012, passim, con puntualizaciones generales relevantes en la introducción al volumen a cargo de Bénatouïl y Bonazzi 2012.

${ }^{5}$ Arendt $1977^{2}$, p. 93; cf. Birmingham 1999, pp. 32-33, que destaca un aspecto activo en la función de los espectadores en tanto que eran quienes juzgaban respecto de las acciones realizadas por quien actuaba. La vinculación entre los problemas de la teoría, la filosofía y la visión había sido destacada ya por Jaeger 1957, p. 10.

${ }^{6}$ La posible conexión ha sido puesta en duda por Chantraine 1968-1980, s. v. Өعw@ós. 
la asociación entre estas dos figuras del observador en la Grecia antigua no resulta para nada forzada si seguimos las controversias actuales, aunque es menos claro si ambos términos pueden históricamente remitir a lo mismo.

La actividad propia del $\theta \varepsilon \omega \varrho o ́ \varsigma$ es lo que denota el nombre de acción $\theta \varepsilon \omega \varrho i ́ \alpha$. Como se deduce de la visión histórico-filosófica de Arendt, ${ }^{7}$ se puede afirmar que el término constituye claramente un artefacto platónico, empleando una expresión acuñada por Barbara Cassin para la sofística. ${ }^{8}$ En efecto, como ya había advertido André Festugière, el significado

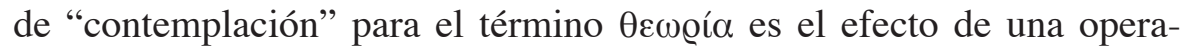
ción platónica, principalmente en el marco de la teoría de las formas planteada por el filósofo. ${ }^{9}$ Pierre Chantraine extrae las consecuencias etimológicas al precisar que el sentido de contemplación se desarrolla a partir de Platón; luego, ya en la época helenística, teoría y especulación comienzan a definirse en oposición a práctica. ${ }^{10}$ La fuerza del filtro platónico es tal que puede llevarnos a pensar que desde siempre $\theta \varepsilon \omega \varrho i ́ \alpha$ implicó en la Grecia antigua este sentido contemplativo. Platón inaugura, pues, la idea de $\theta \varepsilon \omega \varrho i ́ \alpha$ como reflexión situada en trascendencia respecto de lo observado.

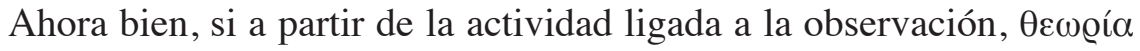
puede remitir a una concepción según la cual se contempla y se interpreta el mundo, esto implica una operación que en sí misma contiene ya un supuesto: hay un mundo que la palabra nombra; hay un mundo con respecto al cual la palabra se halla capacitada para darle un orden mediante una interpretación que lo vuelva inteligible. No es que el mundo sea simplemente reflejado por aquel que observa; pero el régimen de la interpretación entraña en buena medida predicar la existencia del mundo como asunción más general, allende la palabra misma que lo hace percibir como ordenado. En efecto, $\theta \varepsilon \omega \varrho i ́ \alpha$ se relaciona con una concepción en la que la intelección del mundo implica una representación que supo-

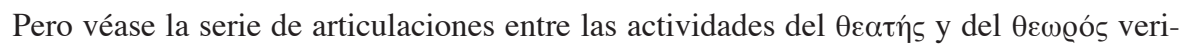
ficadas por Rehm 2002, pp. 3, 297-298, n. 14.

${ }^{7}$ Arendt 1958, pp. 14-16, 20, 301-302.

${ }^{8}$ Cassin 1995, pp. 24-25.

${ }^{9}$ Festugière 1936, passim y esp. pp. 31, 189, 390-391.

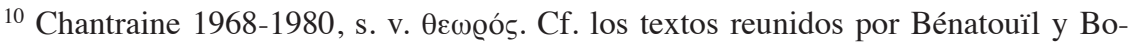
nazzi (eds.) 2012, pp. 1-117. 
ne un vínculo con ese mundo y que involucra un trabajo a partir de un zócalo dado sobre el cual se establece la interpretación. ${ }^{11}$

Dicho en otros términos, la interpretación hace ver, es decir, permite hablar de un objeto, visibilizándolo, volviéndolo representable. Pero el régimen de existencia de ese objeto transcurre en un plano distinto del de la palabra que lo dice. La fuerza que lo instituye no es de la misma cualidad que la del significante que lo ordena; de allí la representación. Este primer acercamiento al término $\theta \varepsilon \omega \varrho i ́ \alpha$ nos revela, pues, que esta noción se halla fuertemente marcada con el sentido de realizar una observación en posición contemplativa, trascendente, haciendo que el agente devenga un observador que no participa de lo visto y que lo observado resulte una suerte de representación del objeto contemplado. Así, bajo los modos de la teoría y la especulación, la tradición de nuestro pensamiento asume la existencia de una reflexión que consistiría en el acto mismo de observar y en la actividad inherente al observador.

Pero, ¿cuál era la inscripción específica que el término tenía antes de Platón? Andrea Nightingale ha señalado que en la Grecia antigua hubo

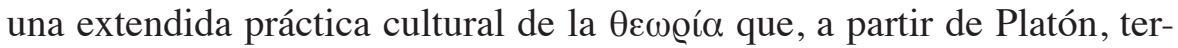
minó siendo apropiada por la filosofía con un sentido específico. La base

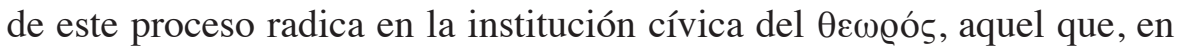
calidad de embajador oficial, viajaba de una ciudad a los oráculos y/o los festivales religiosos y de regreso exponía su reporte de testigo ocular. El aspecto central de esta práctica era que, al participar de una situación sacralizada por medio de ritos, lo que se configuraba era una suerte de

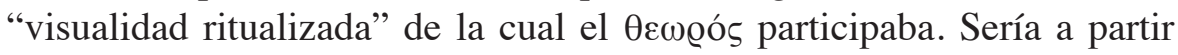
de esta configuración que la filosofía construiría su concepción de la $\theta \varepsilon \omega \varrho i ́ \alpha$, apropiándose del término: la peregrinación física a un santuario daría paso así a la búsqueda metafísica de la verdad. En cualquier caso, no es sino hasta el siglo IV que el sentido de contemplación como interpretación filosófica que ordena y vuelve inteligible el mundo se puede asociar con la idea de $\theta \varepsilon \omega \varrho i ́ \alpha .{ }^{12}$

${ }^{11}$ Marin 1993, pp. 10-11, lo ha indicado con precisión a propósito de los poderes de la imagen: se trata de la re-presentación que supone presentar algo de nuevo en el tiempo y/o en el espacio, pues el prefijo re- introduce una sustitución. Algo que estaba presente y ya no lo está más es entonces re-presentado; hay por ende un ausente en el tiempo y/o en el espacio, en cuyo lugar hay un otro que lo sustituye.

${ }^{12}$ Nightingale 2004, pp. 40-93. Cf. P1., R., libro I, esp. 327a, 328a y 354a, donde se representa el paso de la observación de un festival a la observación filosófica. En Pl., $R$., 
La historia de este término permite desacoplar sus diferentes sentidos pero también ver cómo se encabalgan, de forma tal que podemos situarnos, de acuerdo con los fines que aquí nos proponemos, en el momento previo a su configuración como artefacto platónico. Puesto que $\theta \varepsilon \omega \varrho i ́ a$ nos confronta con una práctica específica de carácter cívico, político, religioso y cultural cuyo agente es el $\theta \varepsilon \omega @ o ́ s$, conviene que tengamos presente las peculiaridades de esta figura del observador en la medida en que las características centrales de su actividad se han asociado con las

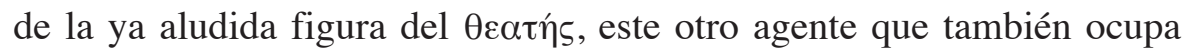
un lugar fundamental en la actividad cultural griega y que, como ya hemos indicado, soporta asimismo la idea de espectador que de modo genérico se atribuye a la figura del $\theta \varepsilon \omega @ o ́ s .{ }^{13}$

Si creíamos que la apropiación platónica había quedado restringida nada

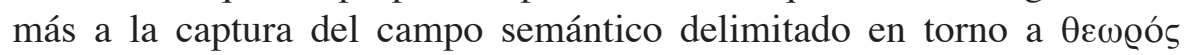
y $\theta \varepsilon \omega \varrho i ́ \alpha$ para la contemplación filosófica, pues no es así. Según Sara

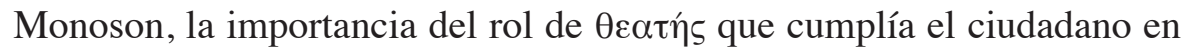
la democracia ateniense es algo que subyace en la apropiación platónica del vocabulario de la representación teatral, en especial en la República donde el filósofo aparece como un $\theta \varepsilon \alpha \tau$ ‘. Platón respeta la asociación del vocabulario teatral con una actividad intensa y no sólo con la experiencia sensorial de "ver" pasivamente. ${ }^{14}$ Pero hace de la filosofía un tipo más refinado de intervención del público (audience performance), sugiriendo así que el filósofo estaría tratando de ocupar el rol cívico que normalmente se asocia con los $\theta \varepsilon \alpha \tau \alpha i ́$ en una competencia dramática. Claro que Platón hallaría también un aspecto negativo en el protagonismo de los $\theta \varepsilon \alpha \tau \alpha i ́$ en el contexto de la democracia, asunto sobre el que volveremos luego.

Ahora bien, si la resignificación platónica del campo semántico ligado a las nociones que delimitan al observador conlleva tanto su desempeño

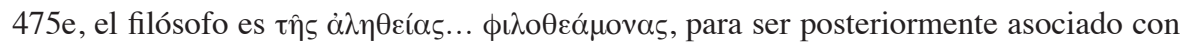
la $\theta \varepsilon \omega \varrho i ́ a$ de todo tiempo y ser, Pl., R., 486a, y de lo divino, Pl., ibid., 517d.

${ }^{13}$ Cf. Rocco 1997, pp. 109-110, n. 10.

${ }^{14}$ Monoson 2000, pp. 88-110, 206-238. Cf. Pl., R., 369a, 372e, 402d, 525a, 532c, $545 \mathrm{c}, 576 \mathrm{e}, 579 \mathrm{e}, 582 \mathrm{c}, 611 \mathrm{~b}-\mathrm{d}$. 
de carácter contemplativo como su conducta pasiva respecto de lo que se constituye en objeto de contemplación, ¿ocurre lo mismo con los espectadores en el marco de la experiencia teatral, mostrando también éstos una actitud pasiva, tal como se desprendería de la cita de Diógenes Laercio? Pero en caso de ejercer un rol activo, que es la postura que aquí vamos a argumentar, ¿en qué consistiría la actividad del espectador en relación con el espectáculo? Una de las interpretaciones más extendidas es la que sostiene la existencia de una homología en la Atenas democrática entre la participación colectiva en la asamblea y la audiencia del teatro, pues se trataría de los mismos integrantes del cuerpo cívico considerados según sus roles respectivos de ciudadano y de espectador. Esta homología abarcaría también a los espacios de reunión en público: la Pnyx, el ágora y el teatro de Dioniso. ${ }^{15}$ Simon Goldhill lo destaca con fuerza al plantear que en Atenas los ciudadanos eran $\theta \varepsilon \alpha \tau \alpha i ́$ que actua-

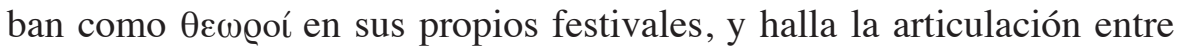

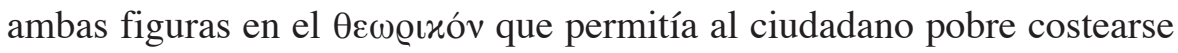
su entrada al teatro. De allí su capacidad para la $\theta \varepsilon \omega \varrho i ́ \alpha$, pues sentarse como espectador para evaluar y juzgar implicaba participar como sujeto político, en la medida en que la $\theta \varepsilon \omega$ oía enfatizaba el rol del espectador como un factor clave en la construcción de la cultura democrática. ${ }^{16}$

Andrea Nightingale reconoce los aportes de estos enfoques que homologan al ciudadano con el espectador en función del análisis de los discursos y las prácticas de la democracia ateniense. Sin embargo, expone una crítica a esta visión haciendo particular referencia a la interpretación de Goldhill, enfatizando la diferencia fundamental entre el rol del ciu-

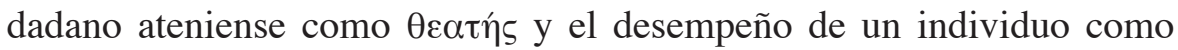
$\theta \varepsilon \omega \varrho o ́ s$, que hacía especialmente un viaje para observar las prácticas ritualizadas desarrolladas en un santuario o en un festival. Para Nightinga-

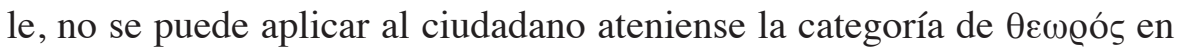
sus propios festivales, puesto que la evidencia apunta fundamentalmente

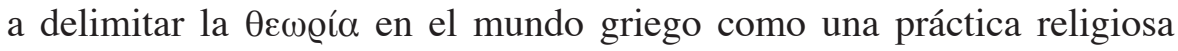
con carácter internacional y transcultural, y no en exclusiva referencia a la situación institucional y simbólica de la Atenas clásica. ${ }^{17}$

15 Goldhill 1987 y 1997; Ober 1989, pp. 104-155; Ober y Strauss 1990; Henderson 1990; Monoson 2000, pp. 88-110; Dobrov 2001; Slater 2002; Rehm 2002; Roselli 2011.

${ }^{16}$ Goldhill 1999, pp. 5-8.

${ }^{17}$ Nightingale 2004, pp. 49-52. Nightingale también plantea como argumentos el 
Por su parte, Nicole Loraux ha planteado una crítica de índole general a la idea de una homología entre el ciudadano y el espectador en la Atenas clásica, sosteniendo que, en virtud de un doble desplazamiento que se lleva a cabo prácticamente en el mismo momento, tanto el teatro de Dioniso como el lugar de reunión de la asamblea dejan de estar situados en el ágora, el centro político por excelencia en la época arcaica. En el primer caso, su ubicación estuvo desde entonces al pie de la Acrópolis; en el segundo caso, en la colina llamada Pnyx. Estas reconfiguraciones del espacio son para Loraux un síntoma del hecho fuerte de que la política no era parte del teatro, en tanto que la representación de la política que la ciudad aceptaba e impulsaba era la de una unidad ideológica sin conflicto cuyo lugar institucional sería la asamblea. En todo caso, lo que el teatro, la tragedia en particular, pondría en escena sería una anti-política, una política en oposición a otra bajo el modo del "anti", destacando el carácter sedicioso de la política que la ideología oficial de la unidad cívica rechazaría. Loraux lo señala gráficamente: el movimiento es del ciudadano al espectador. A medida que se afirmaba la separación espacial entre el ágora, el teatro y la asamblea también se afianzaba el hecho de que los atenienses eran ciudadanos o espectadores conforme no a una relación de homología, sino a una distancia entre las prácticas respectivas sin posibilidad de sutura. Dicho de otro modo, había una tensión entre las mismas: se era ciudadano por la pertenencia cívica a la comunidad política; en cambio, se era espectador por la pertenencia genérica a la raza de los mortales. ${ }^{18}$

¿Cuál ha sido, realmente, el comportamiento de los atenienses? ¿Actuaron o no de la misma manera, según un doble rol que les vendría conferido por el hecho de participar en las asambleas y en las audiencias teatrales? Veamos una situación que nos confronta con este doble papel. Se trata del relato de Heródoto (VI, 21, 2) sobre los efectos que las noticias de la derrota de los milesios por los persas produjeron en Atenas a comienzos del siglo v a. C.:

costo elevado de la entrada al teatro, por lo cual sólo asistían a los espectáculos los

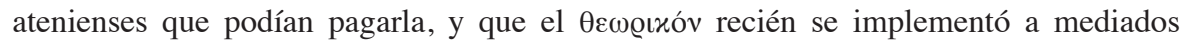
del siglo IV, indicando que si este subsidio a los pobres hubiera existido antes éstos lo habrían usado para sufragar sus necesidades inmediatas. Todo esto apunta a disminuir la presencia del pueblo en el teatro. De haber sido así, no se entendería muy bien, como veremos en breve, la crítica de Platón al pueblo espectador ni su uso del término

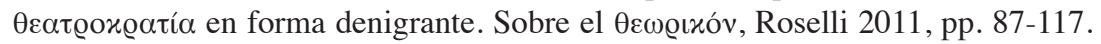

${ }^{18}$ Loraux 1999, pp. 28-44, 120-137. 
Los atenienses, en efecto, pusieron de relieve, de muy diversas maneras, el gran pesar que sentían por la toma de Mileto; $y$, concretamente, cabe señalar que, con motivo de la puesta en escena de La toma de Mileto, drama que

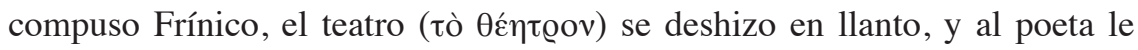
impusieron una multa de mil dracmas por haber evocado una calamidad sentida de carácter nacional; además, prohibieron terminantemente que en lo sucesivo se representara dicha obra. ${ }^{19}$

Si la reacción de los atenienses como espectadores, o como teatro según la designación colectiva usada por Heródoto, fue la de un duelo intenso, su reacción posterior como ciudadanos tras haber visto la representación - probablemente en la asamblea que se realizaba después de los festivales para evaluar su desarrollo - ${ }^{20}$ fue la de impedir que se pudiera recordar en el teatro un hecho luctuoso que consideraban propio: como espectadores prorrumpieron en lágrimas; como ciudadanos decidieron olvidar el evento aciago que les recordaba la derrota. ${ }^{21}$ En lo que sigue buscaremos responder a la cuestión planteada a fin de poder determinar si este doble registro que testimonia Heródoto con respecto a la actividad de los ciudadanos atenienses implica un distanciamiento entre política y teatro, tal como proponía Loraux, o una correspondencia que los constituía en sujeto político, tal como argumentaba Goldhill.

\section{III}

En todas estas discusiones ninguno de los autores citados ha prescindido de recurrir a un famoso pasaje de Tucídides (III, 38, 3-7); nosotros tampoco nos privaremos de hacerlo:

La ciudad, en este tipo de certámenes (ỏ $\gamma(\hat{v} v \omega v)$, concede los premios a otros, y ella sola carga con los riesgos. Pero los responsables sois vosotros

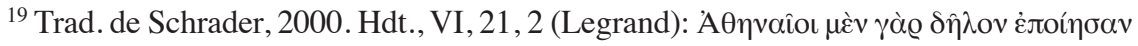

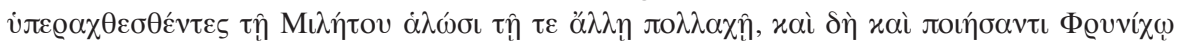

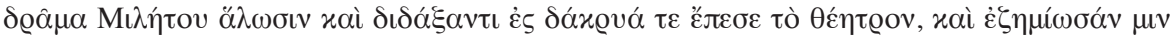

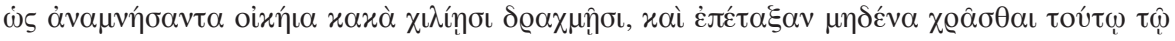

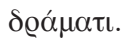

${ }^{20}$ Respecto de estas asambleas, ver Wilson 2000, pp. 166-167 y nn. 54-56; Villacèque 2013, pp. 139-144.

${ }^{21}$ Cf. Loraux 1990, pp. 19-20; 1997, pp. 148-149; 1999, pp. 68-70. 


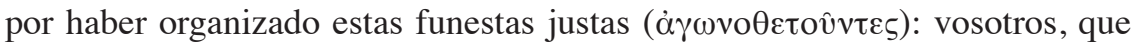
habitualmente sois espectadores de discursos ( $\theta \varepsilon \alpha \tau \alpha \grave{~ \tau o ̂ v ~} \lambda$ ó $\gamma \omega v)$ y oyentes

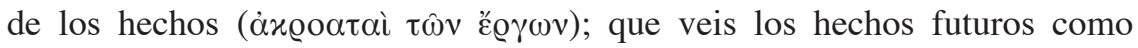
posibles a partir de las hermosas palabras de quienes saben hablar, y los ya ocurridos los juzgáis a partir de las críticas bellamente expuestas, sin otorgar más crédito a lo que ha sucedido ante vuestros propios ojos (ö $\psi \varepsilon \iota)$ que a lo

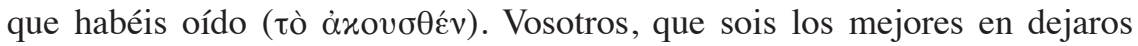
engañar por la argumentación más novedosa y en no querer adheriros a lo ya probado: esclavos como sois de las originalidades de cada momento y menospreciadores de lo habitual. [...] Buscáis, por así decir, un mundo distinto de aquel en que vivimos, sin capacidad siquiera de pensar de modo

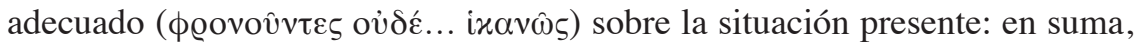
dominados por el placer del oído, os asemejáis más a un público que asiste a

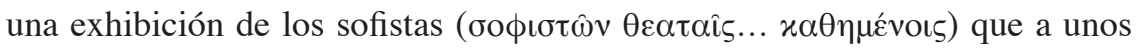
ciudadanos que deliberan sobre la suerte de su ciudad. ${ }^{22}$

Este fragmento forma parte de la pieza oratoria que Tucídides le atribuye a Cleón en el debate sobre Mitilene, ${ }^{23}$ en concreto, durante la segunda asamblea llevada a cabo para revisar la decisión de dar muerte a los mitileneos que se habían rebelado contra el poder imperial ateniense. Cleón intentaba conservar la decisión tomada en la anterior reunión de

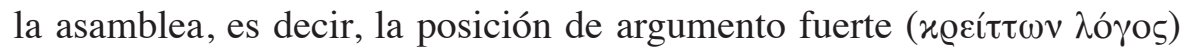
lograda entonces que se sustentaba en el voto mayoritario que su propuesta había obtenido, puesto que se había constituido en el parecer ya establecido de la comunidad. ${ }^{24}$ Aun cuando su discurso ensayase una de-

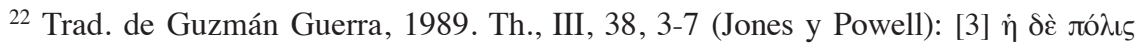

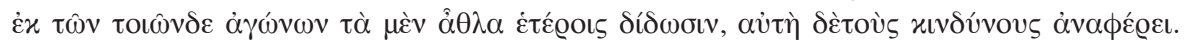

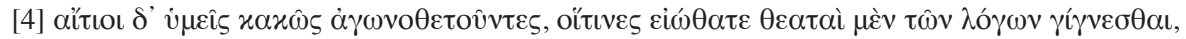

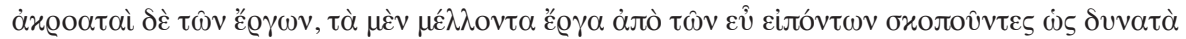

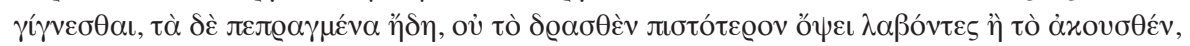

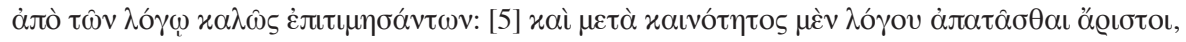

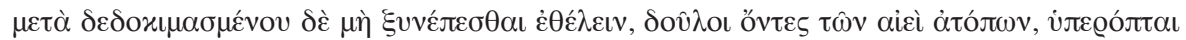

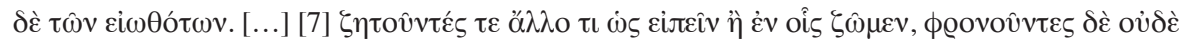

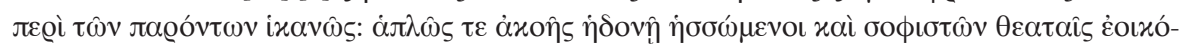

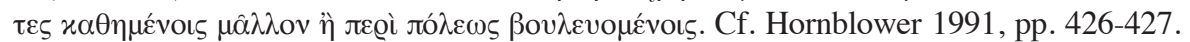

${ }^{23}$ Sobre este discurso en el contexto de la visión tucididea de los liderazgos en Atenas, cf. Andrews 2000.

${ }^{24}$ Cf. Orwin 1984, p. 315: "Cleon's aim in eulogizing law is simply to discredit deliberation, by placing the result of yesterday's discussion beyond any further discussion"; Mara 2008, p. 246: "And nomos is simply the assembly's prior decision to destroy Mytilene made under the influence of his own rhetoric". 
sautorización de los oradores atenienses y su público, que John Hesk ha analizado bajo el modo de una retórica de la anti-retórica, ${ }^{25}$ su oratoria era consecuente con la idea de situarse en el punto de fijación de la ley: si bien la decisión que defendía había sido tomada según la forma que ahora criticaba, su accionar se encaminaba a no hacer lugar a un cambio de decisión. Para muchos estudiosos este pasaje plantea una asociación entre la capacidad inherente a los ciudadanos de deliberar y decidir en la asamblea y su actuación como espectadores en el teatro, ${ }^{26}$ pues lo que trasunta el argumento de Cleón es que esos espectadores de discursos eran los que decidían, y éste es el hecho cardinal de la democracia basada en la producción política de la asamblea.

Pero no todos han estado de acuerdo con la interpretación mayoritaria del uso de $\theta \varepsilon \alpha \tau \alpha i ́$ en el discurso de Cleón. Para Andrea Nightingale, el sentido que adquiere $\theta \varepsilon \alpha \tau \alpha i ́$ en el pasaje citado no implica la existencia de una homología entre la conducta de los ciudadanos en la asamblea y la de los espectadores en el teatro, puesto que la referencia al hecho de ser espectadores de los sofistas no conlleva una semejanza con la práctica teatral sino que sería algo propio del ágora o del ámbito privado. ${ }^{27}$ Esto supone asignar a los $\theta \varepsilon \alpha \tau \alpha$ ú un rol enteramente pasivo, ${ }^{28}$ siguiendo literalmente los argumentos de Cleón acerca de la capacidad de los oradores para pergeñar argumentos y la ineptitud de la audiencia que se sometería mansamente al engaño. ${ }^{29}$ Como señala Victoria Wohl,

${ }^{25}$ Cf. Hesk 1999; 2000, p. 249; 2007, p. 362.

${ }^{26}$ Cf. Ober y Strauss 1990, p. 247; Strauss 1993, p. 55; Monoson 2000, pp. 88-90; Dobrov 2001, p. 6; Slater 2002, p. 73; Garver 2009, p. 17 y n. 20.

${ }^{27}$ Nightingale 2004, p. 51, n. 40.

${ }^{28}$ Al respecto, Lang 1972, pp. 163-164; Cohen 1984, pp. 46-49; cf. Saetta Cottone 2007, § 23 y n. 27.

${ }^{29}$ Cf. Th., III, 37, 5 (trad. de Guzmán Guerra, 1989): "Precisamente así, pues, debemos comportarnos nosotros: sin dejarnos arrastrar por la habilidad oratoria en contiendas de ingenio, daros a vosotros, pueblo de Atenas, consejos contrarios a nuestra

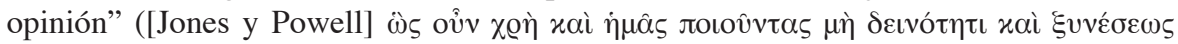

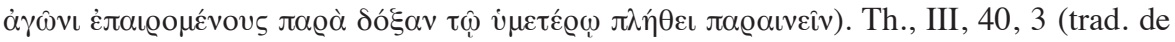
Guzmán Guerra, 1989): "Por su parte, los oradores que os deleitan con sus discursos tendrán su certamen en ocasiones menos importantes, y no en una en la que la ciudad pagará alto precio por deleitarse un poco, mientras que ellos obtendrán un buen benefi-

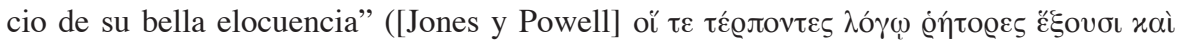

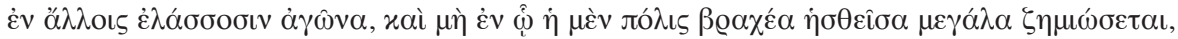


el hecho de que el pueblo fuera responsable de haber organizado las competencias (á $\gamma \omega v 0 \theta \varepsilon \tau o v ̂ v \tau \varepsilon \varsigma)$ en las que actuaba como espectador y oyente no supone pasividad de su parte, sino una actividad bien precisa en la que ocupaba la posición de poder, que llevaba a Cleón a la paradójica situación de tratar de volverlo favorable a su propuesta intentando persuadirlo, pero pidiéndole que se resistiera y fuera fuerte ante la bella aunque engañosa elocuencia de los oradores. Como si Cleón estuviera fuera de la serie de aquellos a quienes reprochaba el uso de hermosas palabras, críticas expuestas bellamente, argumentaciones novedosas. ${ }^{30}$ Como veremos, la respuesta de Diódoto y el voto mayoritario a favor de su postura confirmarán la importancia de la persuasión y la capacidad de decisión del pueblo. ${ }^{31}$

Si el discurso de Cleón puede dar lugar a la idea de un papel pasivo de los ciudadanos como espectadores, en boca del ateniense en las Leyes de Platón (700e-701b) resulta ser lo opuesto, en una crítica de la teatrocracia como situación directamente ligada a la democracia:

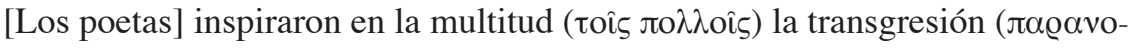
$\mu$ úav) hacia la música y la osadía ( $\tau$ ó $\lambda \mu \alpha v$ ) de creerse capaces de juzgar. De

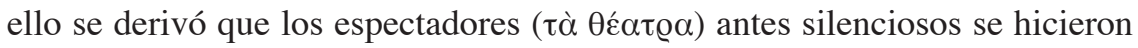
vocingleros ( $\dot{\varepsilon} \xi \dot{\alpha} \phi \omega ́ v \omega v \phi \omega v \eta ́ \varepsilon v \tau \alpha)$, como si entendiesen lo que en música está bien o no, y en lugar de la aristocracia se produjo en ese campo una

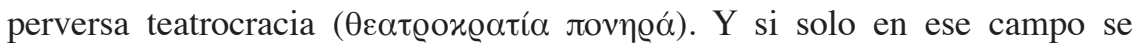
hubiese producido una democracia de hombres libres no hubiera sido el hecho tan terrible. Pero lo cierto es que a partir de la música comenzó entre

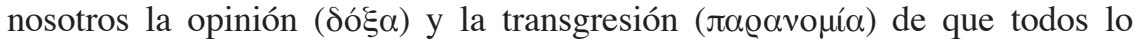
sabían todo, con lo cual vino la libertad ( $\dot{\lambda} \lambda \varepsilon v \theta \varepsilon \varrho i ́ \alpha)$. Quedaron sin miedo

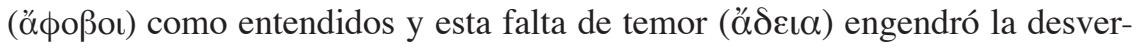

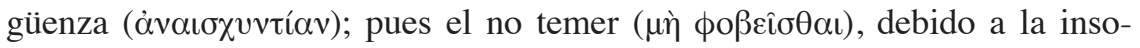
lencia $(\theta \varrho \alpha ́ \sigma o \varsigma)$, la opinión del más calificado es en sustancia la perversa

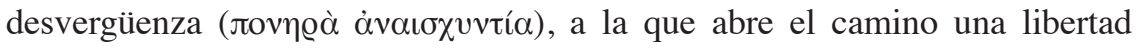

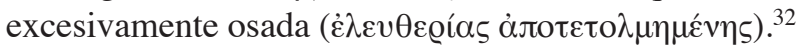

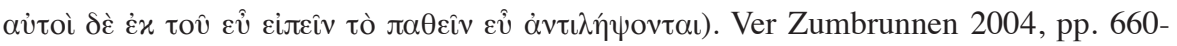
$662,674$.

${ }^{30}$ Wohl 2002, pp. 93-98; cf. Roselli 2011, pp. 69-70.

${ }^{31}$ Para el conjunto del debate sobre Mitilene, véase ahora el completo análisis de Harris 2013.

32 Trad. de Pabón y Fernández-Galiano, 1983 [modificada]. Pl., Lg., 700e-701b (Bur-

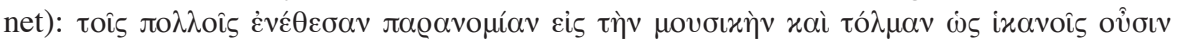


Así pues, no importaría tanto, o, mejor dicho, no sólo sería importante el papel de quienes ofrecían sus composiciones como espectáculo, sino también la capacidad de decisión adquirida por la masa, su libertad para opinar sobre todas las cosas. Como ha demostrado claramente Robert Wallace, ${ }^{33}$ el problema que suscita el texto platónico es el de la actuación del público en el teatro (audience performance), que conforme al pasaje citado no resultaba para nada pasiva, sino muy vigorosa, hasta el punto de interrumpir a veces el desarrollo de la obra apelando al grito ( $\theta$ ó en la asamblea o en los tribunales. ${ }^{34}$ Como ha comprendido sutilmente Jacques Rancière, la teatrocracia es el efecto del ruido de la multitud, del griterío y el aplauso que constituyen su participación: "El poder está menos en el espectáculo que en el alboroto que autoriza. En el ruido de los aplausos, la multitud expresa solo su propia esencia". ${ }^{35}$

En este sentido, retengamos un aspecto primordial del pasaje de las Leyes: el poder de la audiencia se equipara con el del pueblo, pues ambos se componen de la misma multitud (oi ro $\lambda \lambda$ oí) en contraposición con los aristócratas que pierden la capacidad de mando. Este cambio habilitado por la presencia de la multitud en los espacios públicos, que en el texto platónico aparece organizado históricamente, procede del hecho de que quienes antes carecían de voz comienzan precisamente a tener su propia voz. Todo esto se piensa como un quebrantamiento del orden natural, una dominación del pueblo cuyos efectos políticos son la

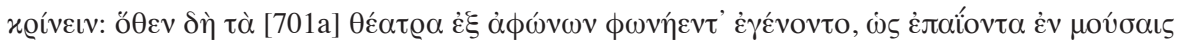

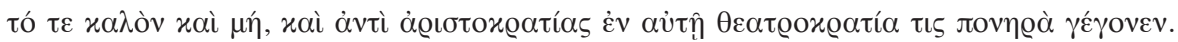

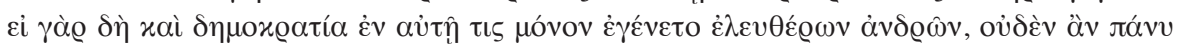

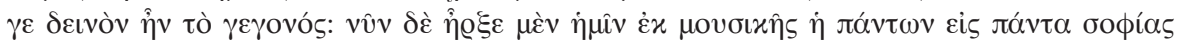

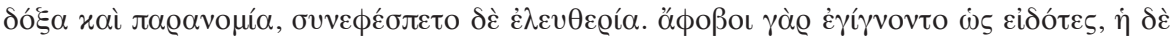

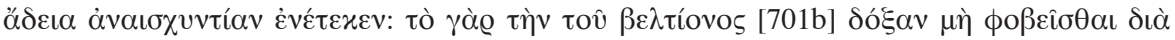

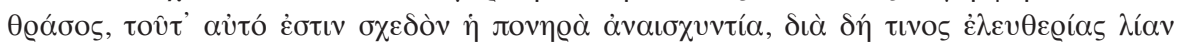

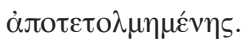

${ }^{33}$ Wallace 1997. Sobre el bullicio en los ámbitos de reunión pública (teatros, asambleas, tribunales, etc.), cf. Pl., Prt., 319c; R., 492b; D., In Midiam (XXI), 226; Poll.,

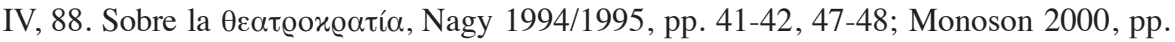
104-105; Weber 2004, pp. 31-53; Wright 2009, pp. 150-153; Roselli 2011, pp. 57-58, 192-193. Sobre la facultad de la audiencia para evaluar y decidir sobre el espectáculo teatral, Revermann 2006.

${ }^{34}$ Cf. Bers 1985; Tacon 2001; Villacèque 2013b.

35 Rancière 2013 [2002], pp. 61-63 (cita en p. 63); cf. Hallward 2006; 2009. 
teatrocracia y la democracia de hombres libres, ambas productos de la opinión ( $\delta$ ó $\xi \alpha)$, la transgresión ( $\pi \alpha \varrho \alpha v o \mu i ́ \alpha)$ y la libertad excesivamente osada ( $\dot{\varepsilon} \lambda \varepsilon v \theta \varepsilon \varrho i ́ \alpha$ ó orden natural de la dominación aristocrática es juzgado según sus efec-

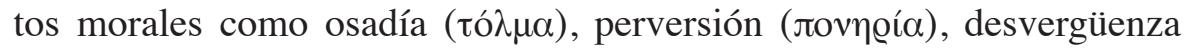

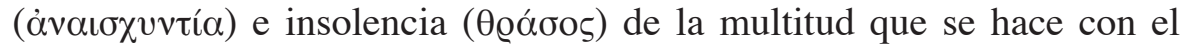
poder de decidir sobre todas las cosas. ${ }^{36}$ Fundamental para que irrumpa esta capacidad de la multitud para decidir sobre todos los asuntos pú-

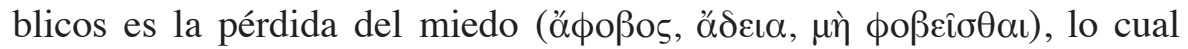
constituye la base del empoderamiento político del pueblo que le permite desligarse de la tutela aristocrática.

Dejando de lado el sentido crítico y peyorativo de la visión platónica y asumiendo positivamente la conjunción entre teatrocracia y democracia, un ámbito privilegiado para comprobar esta articulación resultan las representaciones de las comedias de Aristófanes. Thomas Hubbard ha puesto claramente de relieve la importancia asignada en éstas a los

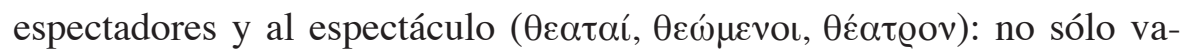
rios de los protagonistas y de los coros cómicos juegan este doble rol que implica observar y ser observado, sino también espectadores de la audiencia son introducidos en el espectáculo en las parábasis y en diversos pasajes de las obras. ${ }^{37}$ En algunos de estos casos se trata de breves apelaciones al público para hacerlo partícipe de la trama, involucrándolo en tanto que audiencia de un espectáculo teatral, destacando su habilidad o inteligencia, pero también sus errores o debilidades. ${ }^{38}$ En otros casos, la implicación trasciende el contexto de la trama de la obras para reponer a los espectadores en el lugar de los que deciden o pueden influir en la

\footnotetext{
${ }^{36}$ Según Pl., Lg., 701a (trad. de Pabón y Fernández-Galiano, 1983): "la opinión y la

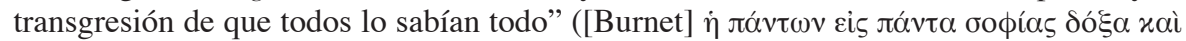
$\pi \alpha \varrho \alpha v o \mu i ́ \alpha)$. Esta crítica se conecta con la que Platón plantea en el Protágoras sobre el hecho de que en la asamblea cualquiera podía pedir la palabra, aconsejar y participar de las deliberaciones (Prt., 319b-d; cf. R., 493c-d). En el mismo sentido se expresa Aristóteles en la Política al criticar la democracia en la que el pueblo era soberano de todas

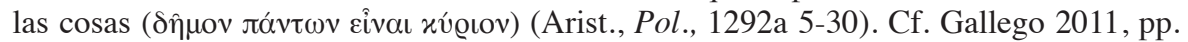
200-210.

${ }^{37}$ Hubbard 1991, pp. 13-15; cf. asimismo Slater 1999 y, sobre todo, Villacèque 2013a, pp. 85-102. También en las tragedias existían formas de implicar a la audiencia: Bain 1975; Villacèque 2007a; 2007b; 2013a, pp. 105-138.

${ }^{38}$ Ar., Ach., 442; Eq., 36, 228, 1220; Nu., 534-535, 889-890, 1096-1110; V., 54-59, 1071; Pax, 43-46, 658, 962-965, 1115; Ra., 1110-1118; Ec., 582-585.
} 
decisión sobre la competencia teatral..$^{39}$ Finalmente, como bien se sabe, la interpelación a los espectadores en las parábasis los convocaba no sólo en tanto que audiencia del teatro, sino también en tanto que ciudadanos, a los que Aristófanes pretendía hacerles notar los conflictos que atravesaban la situación política ateniense y las opciones que deberían ser tenidas en cuenta para llegar a la mejor decisión. ${ }^{40}$

El punto importante es, pues, el siguiente: ¿cuál era el lugar de los ciudadanos y/o de los espectadores en la producción política y/o teatral, respectivamente? El reconocimiento de las características de la actuación de los ciudadanos en la asamblea y de los espectadores en el teatro no deja en claro cuál sería su rol concreto, ni esclarece su incidencia efectiva en términos prácticos en el proceso de producción discursiva. En efecto, según Tucídides en boca de Cleón, los ciudadanos en la asamblea devenían espectadores de discursos no porque fueran pasivos sino porque su actividad en tanto que audiencia consistía en resolver el debate político como si fuera una contienda agonística. ${ }^{41}$ En boca del ateniense, según Platón, Atenas devenía una teatrocracia análoga a la democracia en la medida en que el pueblo dejaba de temer a los superiores y comenzaba a decidir todo, asumiendo un rol activo en el teatro y en la asamblea.

Este es, precisamente, el argumento que Noémie Villacèque sostiene y demuestra detalladamente, analizando el rol del público en el teatro conforme a los modos según los cuales tanto los poetas cómicos como los trágicos se dirigían a los espectadores transformando el espectáculo en deliberación. En este sentido, la afirmación del Cleón de Tucídides respecto de los ciudadanos como espectadores de discursos apunta más a su fuerte rol activo que a un estado de apatía. Pero el otro aspecto implicado es la teatralidad como un factor que atravesaba el desarrollo de la actividad ciudadana en los tribunales así como en la asamblea, convirtiendo la deliberación en espectáculo. El ruido ( $\theta$ ó@vßos) como afirmación de la soberanía popular, indica Villacèque, era un elemento común a las prácticas colectivas en el espacio teatral y en el político. Es

${ }^{39}$ Ar., Ach., 628-635; Nu., 518-527; V., 1009-1023; Pax, 543, 732-738; Av ., 445-446; Ra., 1-2, 908-910, 1475; Ec., 888, 1140-1143; Pl., 797-799.

${ }^{40}$ Ar., Ach., 497-499; Eq., 503-509; Nu., 575-594; Av., 753-768.

${ }^{41}$ Sobre el rol activo de los espectadores, en el teatro y como integrantes del pueblo, Roselli 2011, pp. 1-62. 
por esto que se puede hablar de identidad entre ciudad y escena, de consustancialidad entre ambas, que es lo que Platón criticaba al equiparar democracia y teatrocracia. ${ }^{42}$

Volvamos por un momento a la interpretación de Hannah Arendt citada al inicio. ${ }^{43} \mathrm{Si}$ bien se asociaba a los $\theta \varepsilon \alpha \tau \alpha i ́$ con la contemplación pasiva del espectáculo, no obstante esto, se planteaba también allí una facultad sustentada en la percepción de la verdad, en la medida en que los espectadores tenían acceso a la visión de la totalidad de lo observado. Esto les daría la capacidad de juzgar en función de su parecer ( $\delta$ ó $\xi \alpha$ ), a diferencia del actor que llevaba a cabo su parte en el espectáculo: mientras que éste era activo pero sólo actuaba una parte del todo, en cambio, aquéllos tenían la posibilidad de ver el conjunto y juzgar desde esta perspectiva.

En la Poética (1455a 22-29), Aristóteles atribuía a los $\theta \varepsilon \alpha \tau \alpha i ́$ el poder de decidir sobre la coherencia de lo que sucedía en el espectáculo, sugiriendo al mismo tiempo una relación intrínseca de la audiencia con la verdad de la representación teatral ligada a la observación:

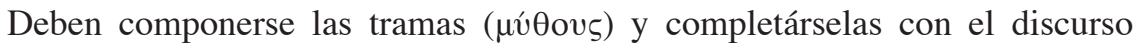

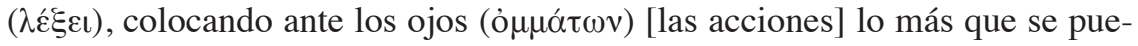
da. Pues de esta manera, al ver[las] (ọ@ôv) con la mayor claridad como si se asistiera a las propias acciones, podrá descubrirse lo que es conveniente y será más difícil que pasen inadvertidas las contradicciones. Prueba de ello es lo que se le objetaba a Carcino, pues Anfiarao salía (ỏvińıı) del templo, cosa que se le pasó inadvertida al no tomar en cuenta al espectador ( $\mu \grave{\text { ò } @ \omega ̂ v \tau \alpha}$ tòv $\theta \varepsilon \alpha \tau \eta ́ v v) ;{ }^{44}$ pero en la escena falló porque a los espectadores $(\theta \varepsilon \alpha \tau \hat{\omega} v)$ eso les molestó. ${ }^{45}$

42 Villacèque 2013a. Este libro está llamado a transformarse en una referencia obligada sobre todos los aspectos implicados en el análisis de las relaciones entre democracia y teatro en la Atenas clásica.

${ }^{43}$ Arendt $1977^{2}$, pp. 93-94.

44 Sobre la lectura tòv $\theta \varepsilon \alpha \tau$ ív y la necesidad de consignar en la traducción la expresión “al espectador", Tarán y Gutas 2012, ad loc. y p. 273; cf. Sinnott 2009, ad loc., n. 440, que sin embargo decide omitirla en su versión.

45 Trad. de Sinnott, 2009 [modificada]. Arist., Po., 1455a 22-29 (Tarán y Gutas):

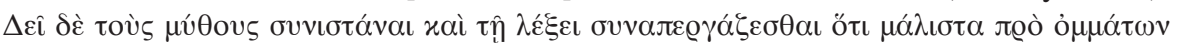

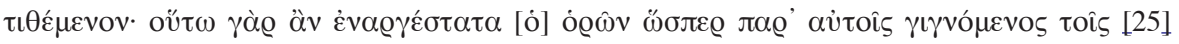

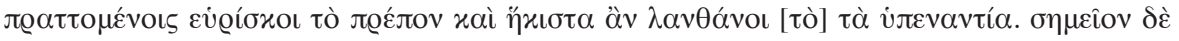


El pasaje es discutido por los especialistas en cuanto al sentido que debe darse al error cometido por el poeta Carcino. Brevemente, el problema radica en si el retorno de Anfiarao significaba su resurrección, debiendo entonces haber vuelto de su tumba y no de un templo (puesto que era un héroe al que se rendía culto), o si el regreso aludido por Aristóteles era su vuelta a escena por un lugar incongruente respecto del sitio por el que había salido previamente, hecho que el público advirtió durante la representación pero que escapó a la perspectiva del poeta. ${ }^{46} \mathrm{Sin}$ pretender intervenir en esta sofisticada discusión, haremos hincapié aquí

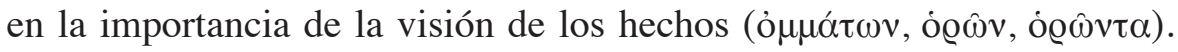
Lo que resulta importante para nuestros fines es que el texto revela la capacidad de los espectadores en el teatro para decidir sobre el espectáculo, considerando la coherencia de la puesta en escena o bien a partir del contraste con los sucesos míticos, que habrían sido alterados por el poeta, o bien según el desarrollo de las acciones de la trama propiamente teatral, cuya secuencia Carcino habría perdido de vista situando a un personaje en un lugar inapropiado. En el teatro, pues, parecería haber un núcleo en relación con el cual contrastar y establecer la verdad de los hechos.

\section{IV}

Pero, ¿qué sucedía cuando los $\theta \varepsilon \alpha \tau \alpha i ́$ no tenían con qué contrastar? Dicho de otro modo: si los atenienses en la asamblea actuaban como $\theta \varepsilon \alpha \tau \alpha \grave{~} \tau \hat{\omega} v \lambda o ́ \gamma \omega v$, ¿cuál era su relación con los hechos que les servían para contrastar y de qué manera se establecía la verdad de los mismos? El problema medular que encierra este interrogante es el de la palabra política en relación con el mundo contingente de la polis, para la cual hemos postulado un carácter performativo, cuya operatoria era definida por el discurso sofístico en torno a lo verosímil (عixós).

Platón se refiere a esta capacidad performativa de la palabra política en el Protágoras (318e-319d), no tanto por lo que pone en boca del sofista como por la reflexión que introduce Sócrates respecto a cómo opera la asamblea cuando se debe pensar y debatir qué hacer. El sofista

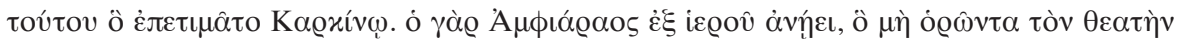

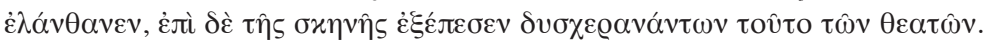

${ }^{46}$ Cf. Green 1990; Davidson 2003. 
afirma que su enseñanza consiste en transmitir el buen discernimiento

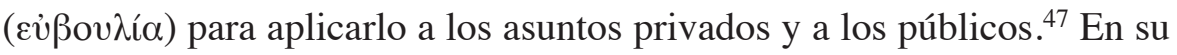
respuesta Sócrates se detiene en estos últimos introduciendo las reunio-

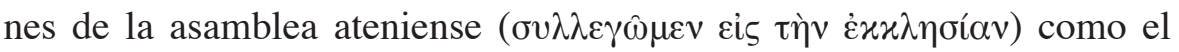
ámbito específico en el que, según la enseñanza del sofista, se pondría en práctica esta capacidad de aconsejar correctamente. Sócrates indica que se convoca allí a todo tipo de especialistas como consejeros ( $\sigma u ́ \mu \beta o v \lambda o \iota)$ para cada aspecto técnico particular que requiere de un saber específico. Y si alguien sin especialización pretende aconsejar ( $\sigma u \mu \beta o v \lambda \varepsilon v ́ \varepsilon ı v)$, no importa cuál sea su posición social o su origen, en la asamblea se ríen

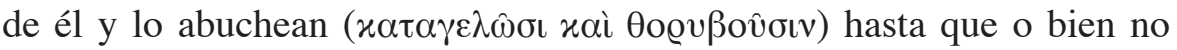
tiene más remedio que callarse debido a las rechiflas, o bien se lo llevan los arqueros a partir de la orden de los prítanos. Así pues, cuando se trata de saberes particulares, en el debate público sólo aconsejan los profesionales.

Pero cuando se trata de algo que atañe al gobierno de la ciudad y es preciso tomar una decisión ( $\beta o v \lambda \varepsilon v ́ \sigma \alpha \sigma \theta \alpha \iota)$, sobre estas cosas aconseja ( $\sigma u \mu \beta o v \lambda \varepsilon v ́ \varepsilon \iota)$, tomando la palabra, lo mismo un carpintero que un herrero, un curtidor, un mercader, un navegante, un rico o un pobre, el noble o el de origen oscuro, y a éstos nadie les echa en cara, como a los de antes, que sin aprender en parte alguna y sin haber tenido ningún maestro, intenten luego dar consejo ( $\sigma u \mu \beta o v \lambda \varepsilon v ́ \varepsilon เ v)$. Evidentemente, es porque creen que no se trata de algo que pueda aprenderse..$^{48}$

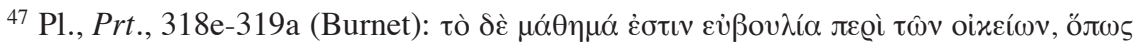

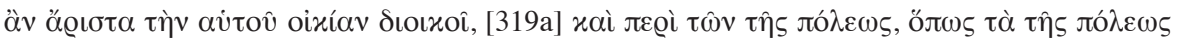

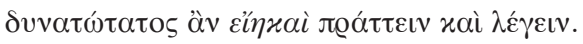

48 Trad. de Calonge Ruiz, Lledó Iñigo y García Gual. Pl., Prt., 319b-d (Burnet): ó@ô

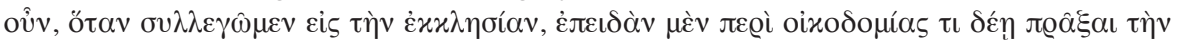

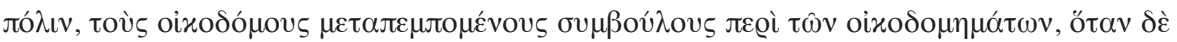

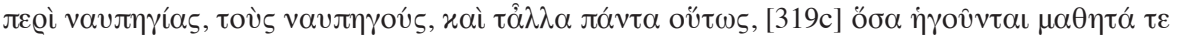

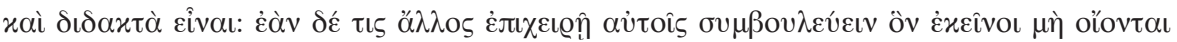

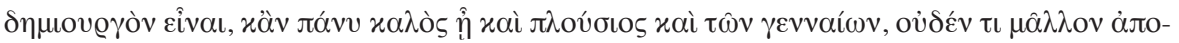

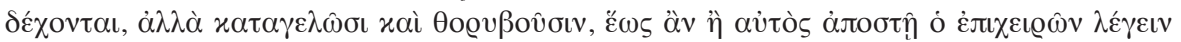

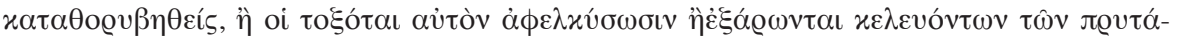

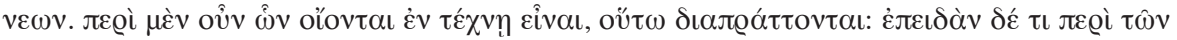

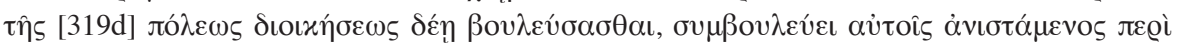

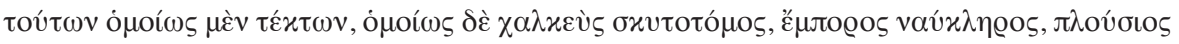

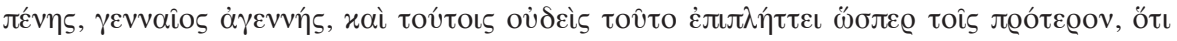


¿Qué tipo de actividad de pensamiento implica, en relación con la práctica de la asamblea, este uso insistente del verbo $\sigma v \mu \beta$ asociación con $\beta$ ov $\lambda \varepsilon v ́ \omega$ del cual deriva y con la clara implicación de que se trata de una actividad colectiva? ¿Por qué puede haber oú $\mu \beta$ ov̀oเ para los temas especializados pero no para el debate de los asuntos públicos - para los que no existen oú $\mu \beta$ ov $\lambda$ o , o todos los ciudadanos lo son por igual-, todo esto bajo la idea puesta en boca de Protágoras de

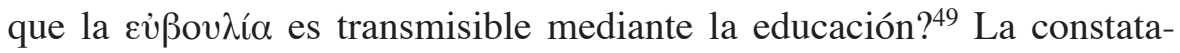
ción inmediata que se desprende es la existencia de una capacidad de discernimiento de la multitud reunida en la asamblea, que sobre cuestiones técnicas sólo admite el consejo de los expertos, al punto de desaprobar con mofa y griterío a quien pretenda usurpar ese lugar reservado a los poseedores de saberes particulares, mientras que sobre decisiones políticas cree que todos poseen la facultad de aconsejar y deliberar sin distinción alguna. Según el Protágoras, en la asamblea la relación entre líderes y multitud, o entre oradores y audiencia, o entre promotores de una propuesta y votantes, implica una posición activa de quienes deciden tanto durante el desarrollo del debate como en el momento de la votación. ${ }^{50}$ La política implica una actividad colectiva e igualitaria de pensamiento que carece, pues, de saber técnico, en la que la decisión como proceso del sujeto se organiza, a un tiempo, como tumulto y deliberación.

Con esta perspectiva de la actividad asamblearia en mente, volvamos ahora al debate sobre Mitilene, en el que, como hemos visto, el Cleón de Tucídides (III, 38, 3-7) comparaba a los ciudadanos en la asamblea con los espectadores, pues hay allí una condición de los $\theta \varepsilon \alpha \tau \alpha i ́$ que se relaciona con la configuración subjetiva de la asamblea. En efecto, la calificación aplicada por Cleón a los atenienses se encuadraba en una consideración general respecto del debate, al que se caracterizaba como

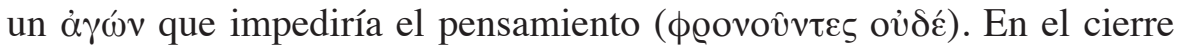
de su discurso Cleón insistía retóricamente, aunque sin acudir al vocablo

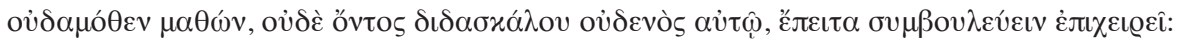

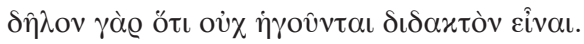

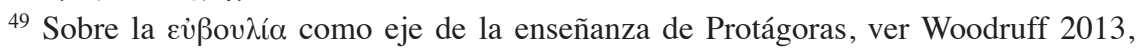
que la relaciona de manera pertinente con lo probable o verosímil (عixós) y con la doctrina de los dos argumentos contrapuestos.

${ }^{50}$ Cf. Villacèque 2013, pp. 43-67. 
$\theta \varepsilon \alpha \tau \alpha i ́$, en la idea de que si los atenienses no hacían lo que él ya les había aconsejado y ahora volvía a proponerles, sólo se deleitarían con el debate de los oradores (Th., III, 40, 3-5). En este contexto, Tucídides ponía en boca de Cleón dos participios con los que alegaba que la suya era una

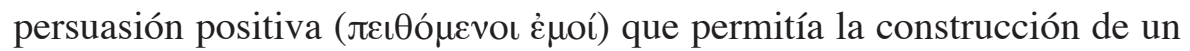

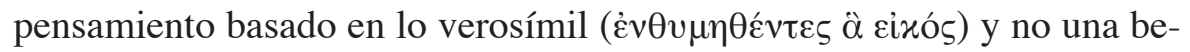
lla elocuencia para los espectadores. Pero ni este argumento, con el que Cleón sustentaba su propia posición, ni el anterior, con el que, como ya vimos, buscaba desacreditar a sus contrincantes pero también al auditorio, parecen contradecir el funcionamiento del dispositivo asambleario: si los ciudadanos considerados como $\theta \varepsilon \alpha \tau \alpha i$ de discursos, o incluso de los sofistas, asistían al enfrentamiento de argumentos era no sólo porque presenciaban el debate, sino porque, una vez persuadidos, en el momento de decidir determinaban la verdad de los enunciados proferidos

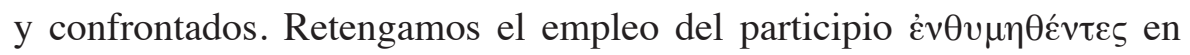
relación con lo que se plantea como un pensamiento bajo condición de la persuasión en un marco asambleario, sobre lo cual volveremos en breve.

En definitiva, la secuencia tucididea exhibe un clara organización sofística del discurso puesto que, como ya dijimos, la alocución de Cleón aparecía como argumento fuerte que buscaba conservar la posición adquirida. Por su parte, el discurso que Tucídides ponía en boca de Diódoto actuaba como argumento débil que trataba de cambiar la situación fijada previamente. Si bien la impugnación de la oratoria ensayada por Cleón parecía dirigirse contra el propio método retórico-sofístico - que permitía construir y deconstruir el parecer de la comunidad otorgando existencia a lo verosímil en la situación-, sin embargo, no tenía otro modo de operar más que argumentando retóricamente. Según Cleón, ante una verdad dada en posición inicial fuerte, que era su propuesta ya votada, se debía dejar las cosas como estaban sin producir nuevos hechos ni alterarlos con palabras. Pero la reapertura del debate - que ya había puesto en suspenso el lugar de argumento fuerte del decreto de la asamblea previa - y la toma de una nueva decisión podrían trazar un rumbo totalmente nuevo o insistir en la línea adoptada. Esto es lo que Tucídides (III, 42, 1-2) le hace decir a Diódoto cuando toma la palabra: ${ }^{51}$

${ }^{51}$ Sobre el rol de Diódoto, Cohen 1984, pp. 49-53; Orwin 1984, pp. 318-324; Price 2001, pp. 89-102; Tritle 2006, pp. 482-485; Mara 2008, pp. 57-61, 98-101, 246-252; Zumbrunnen 2008, pp. 62-65, 80-87; Harris 2013. 
$\mathrm{Ni}$ repruebo a quienes han propuesto de nuevo deliberar sobre los mitileneos, ni alabo a los que censuran que se discuta varias veces sobre cuestiones capitales, sino que pienso que son dos las cosas que más se oponen a una decisión sabia: la precipitación y la ira... Y quien defienda que las palabras

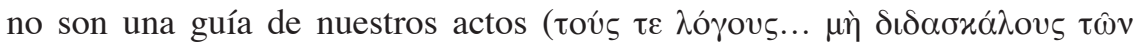

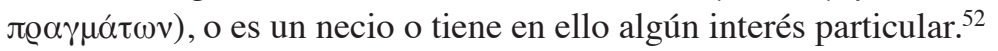

Finalizado el discurso de Diódoto, las palabras han hecho su efecto sobre el público. El trabajo de la división insiste, al punto de que los atenienses se vieron envueltos en un conflicto de opiniones tan contradictorias como las posturas expresadas, que se extendió hasta la votación misma en la que la propuesta de Diódoto resultó finalmente vencedora (Th., III, 49, 1). Pero antes de que la decisión establezca un punto de detención al debate, los enunciados se encuentran en una posición de igualdad, porque ningún discurso detenta de por sí la verdad de la política y nada puede garantizar o dar seguridad alguna a favor de un argumento. El debate ha desinvestido el decreto de la asamblea anterior, quitándole toda la fuerza legal que detentaba desde su entrada en vigencia y produciendo una aniquilación de esta verdad previa. Sólo la persuasión, capaz de generar en la audiencia estados de ánimo favorables a una propuesta $\mathrm{u}$ otra, permite configurar una nueva voluntad mayoritaria. La verdad de un enunciado se decide a partir de un conflicto de opiniones que nos sitúa en el campo de lo verosímil: lo que parece más probable según los efectos de un discurso persuasivo, eso es lo que la comunidad decreta y adopta como parecer y, al votarlo, lo transforma en una ley o decreto resuelto en asamblea.

En la "Oración fúnebre", Tucídides (II, 40, 2-3) ponía en boca de Pericles una visión similar a la de Diódoto en cuanto a la necesidad de valerse del logos para pensar la toma de una decisión. Al mismo tiempo, el pasaje pondera positivamente los efectos políticos del procedimiento asambleario en la medida en que desarrolla un proceso de pensamiento colectivo: ${ }^{53}$

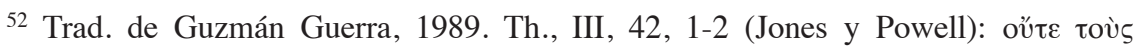

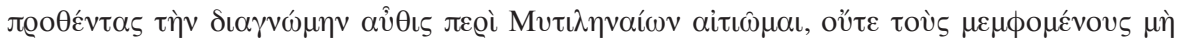

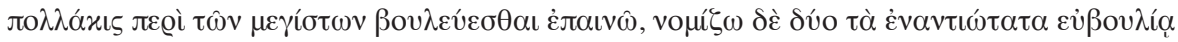

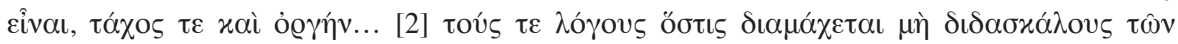

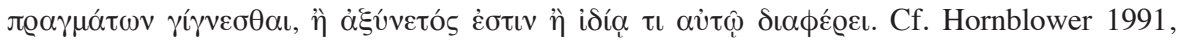
pp. 432-433.

${ }^{53}$ Edmunds 1972; Rusten 1985, p. 18; Hornblower 1991, pp. 304-306; Balot 2001, 


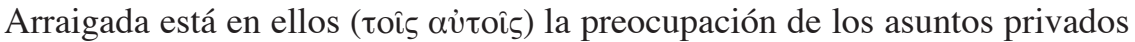

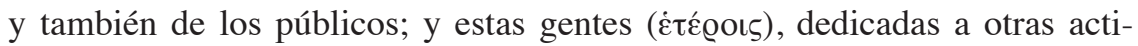
vidades, entienden no menos de los asuntos públicos ( $\mu \grave{\varepsilon} \dot{\varepsilon} v \delta \varepsilon \hat{\omega} \zeta \gamma \nu \hat{\omega} v \alpha \iota)$.

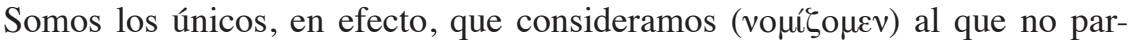
ticipa de estas cosas, no ya un tranquilo, sino un inútil; y nosotros mismos

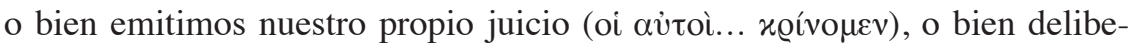

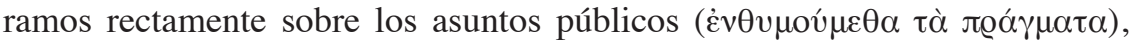

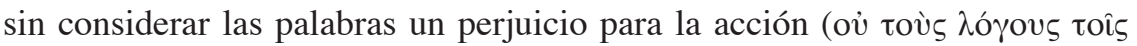

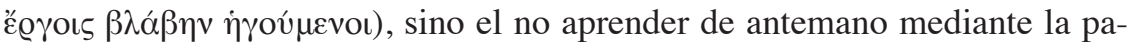

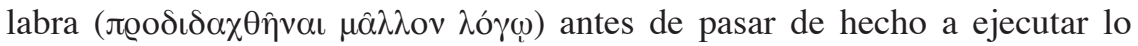
que es preciso. Pues también poseemos, los mismos hombres (oi av̉toí),

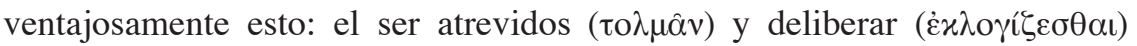
especialmente sobre lo que vamos a emprender... ${ }^{54}$

Una tensión se plantea con fuerza a lo largo del pasaje: la suspensión de la multiplicidad y la heterogeneidad en el espacio público en beneficio de la colectividad; para lo cual no sólo se distinguen los asuntos privados y trabajos particulares respecto de los asuntos políticos, sino que también se contrastan con énfasis en el registro discursivo dos planos enunciativos que nos remiten, respectivamente, a las partes múltiples y a

pp. 508-509; 2014, pp. 25-29; Zumbrunnen 2002, pp. 573, 576. Loraux 1993, pp. 177, 182 , ve en este pasaje un indicio del modo en que la democracia ateniense retoma el antiguo ideal aristocrático del equilibrio entre audacia y razonamiento, acto y palabra; aunque reconoce una vaga alusión a la iơrọía. Esta elucidación de Loraux parece estar atravesada por la idea planteada por Johannes Kakridis, según la cual Pericles invocaría dos tipos de vida al comienzo del capítulo (Th., II, 40, 1-2), la vita contemplativa y la vita activa, combinados de la mejor manera; cf. Rusten 1985, pp. 14-15 y n. 1, que cita y discute la obra de J. Kakridis (Der thukydideische Epitaphios: ein stilistischer Kommentar, München, C. H. Beck, 1961, p. 51 [Zetemata. Monographien zur Klassischen Altertumswissenschaft, 26]), proponiendo que, en realidad, Pericles hace alusión a tres formas de vida (filosofía, riqueza y política) que también son señaladas por Platón $(R ., 581$ c) y Aristóteles (EN, 1095b 14 ss.; EE, 1215a 35), e incluso por Cicerón en el pasaje ya citado en el que transmite la perspectiva de Heráclides Póntico (Cic., Tusc., $\mathrm{V}, 3,8-9)$.

${ }^{54}$ Trad. de Guzmán Guerra, 1989 [modificada]. Th., II, 40, 2-3 (Jones y Powell): ěvı

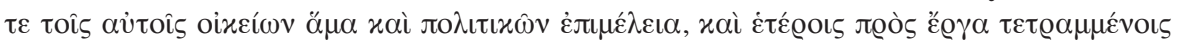

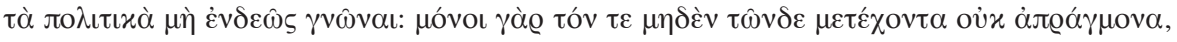

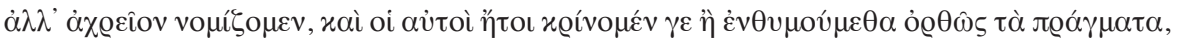

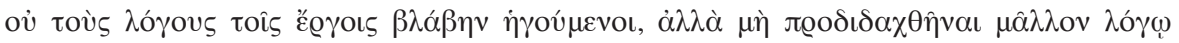

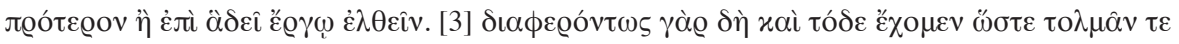

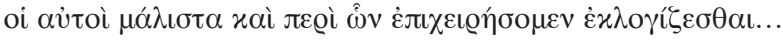


la cohesión del espacio común. ${ }^{55}$ Si para indicar la existencia del plano privado, incluso en relación con lo público, se habla de toîs aủtoîs y de غ̇ंદ́ooıs, cuando el discurso se sitúa exclusivamente en el plano político el "nosotros" es el único modo de enunciación que subsiste mediante el uso de verbos que se conjugan en primera persona del plural y que re-

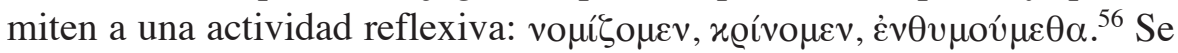
observa con claridad que no se trata de la posesión de un saber sino de la puesta en práctica de un procedimiento de pensamiento, es decir, un análisis concreto de una situación sobre la cual no se posee saber alguno porque implica una circunstancia contingente, que debe ser resuelta con los propios recursos que la situación provee. Esta disposición hace de la asamblea un espacio en el que la existencia de un "nosotros" no se deriva de una sumatoria de individuos con sus determinaciones particulares, sino de una cesación de la heterogeneidad en función de un pensamiento de lo que es común. Alejada se halla esta perspectiva de situar a los atenienses en la asamblea en la posición de meros espectadores.

Ryan Balot señala que el pasaje presenta una tensión entre atributos opuestos e incluso antitéticos (lo privado y lo público), que los atenienses han sido capaces de conjugar. Y concluye que en el discurso de Pericles se busca enfatizar que los mismos hombres son capaces primero de pensar y luego de actuar con coraje. Así, el pensamiento sería un componente del coraje que debería ir acompañado de una predisposición a correr

${ }^{55}$ Cf. Loraux 1993, pp. 190-191, 395-396 (nn. 55-60), que da cuenta de la articulación entre asuntos privados y públicos, entre la multiplicidad de las ocupaciones y la unidad en el plano político.

56 Existe una polémica entre los comentaristas modernos respecto del sentido de estos verbos, en especial los dos últimos, en el pasaje en que aparecen (xaì oi aủtoì

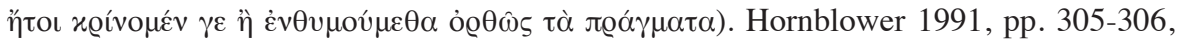
sintetiza los debates ponderando las consecuencias de las diferentes interpretaciones adoptadas que, como indica Loraux 1993, p. 395 (n. 50), giran en torno a interpretar o bien que se alude a una distinción entre los que proponen ( $\dot{v} v v \mu$ ov́ $\mu \varepsilon \theta \alpha)-$ miembros del consejo o simples ciudadanos en la asamblea - y los que deciden (xoívo $\mu \varepsilon v)$, o bien

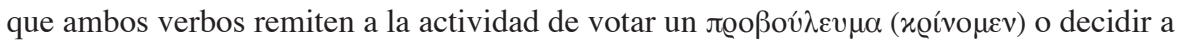
partir de la propia iniciativa $(\dot{\varepsilon} v \theta v \mu o u ́ \mu \varepsilon \theta \alpha)$ en la asamblea. Se podría pensar que el uso

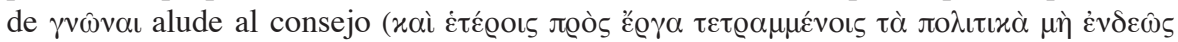
$\gamma v(\hat{v} \alpha \iota)$, en la medida en que, señala Loraux, $\gamma v \omega ́ \mu \eta$ se asocia con $\pi \varrho o \beta o v ́ \lambda \varepsilon v \mu \alpha$ en los decretos atenienses. Pero lo esencial sería que los dos verbos conducen a la actividad de la asamblea, en la que, como se indica en Th., II, 40, 2, o en Pl., Prt., 319b-d, la presencia de trabajadores de todo tipo no inhibe, sino todo lo contrario, la deliberación y la decisión sobre los asuntos políticos. 
riesgos. Balot también arguye que esto no sería una propiedad exclusiva de la representación puesta en boca de Pericles, sino algo inherente a la identidad política y cultural de la democracia ateniense, en la medida en que el coraje, anteriormente parte de las virtudes heroicas, fue resignificado gracias a la democratización producida en el terreno cognitivo y en la práctica militar, de manera que sus cualidades pasaron a caracterizar la actividad de todos los ciudadanos de la democracia. ${ }^{57}$ Es precisamente este coraje ( $\tau o ́ \lambda \mu \alpha)$ lo que Platón encontraba enteramente criticable en la fuerza que adquiría la multitud en el teatro y con el desarrollo de la democracia misma, en la medida en que el pueblo se convertía en la autoridad soberana. En efecto, el mismo término adquiere connotaciones positivas o negativas conforme a las perspectivas de Pericles según Tucídides o del ateniense de acuerdo con Platón. La existencia de este coraje en el pueblo es al mismo tiempo la contracara del miedo: sin este último, dice el filósofo, la multitud se ha apropiado del poder.

Así pues, los atenienses son audaces porque no rechazan pensar las circunstancias, exponer los argumentos y debatirlos, lo cual les permite calcular las acciones a emprender y asumir con responsabilidad la decisión colectiva. ${ }^{58} \mathrm{El}$ uso de la palabra implica tomar un riesgo, que consiste en deliberar e incluso decidir medidas que por su novedad escapan a lo ya establecido. Se trata de otra manera de concebir la palabra: la intervención que hace ser, situada por fuera, para decirlo de algún modo, del régimen de la representación ligado a la interpretación. No se representa mediante la palabra algo exterior a ella misma sino que se produce un mundo por acción y efecto de la palabra. Tal es el carácter performativo e instituyente del discurso que estamos explorando en relación con la toma de la decisión en la asamblea.

En el contexto de esta problemática referida al coraje democrático, no nos parece casual que Tucídides pusiera en boca de Pericles el término $\varepsilon v \theta v \mu o u ́ \mu \varepsilon \theta \alpha$ en referencia a los asuntos políticos, término que nos con-

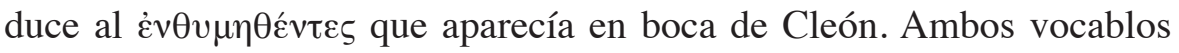

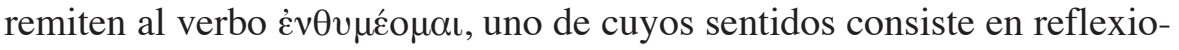

${ }^{57}$ Para la serie de cuestiones planteadas por el autor, ver Balot 2001; 2004a; 2010; 2014, pp. 25-46, 179-197.

${ }^{58}$ Cf. Balot 2004b; 2014, pp. 47-73, sobre el coraje y la libertad de palabra en la democracia ateniense. Ver Landauer 2012, con respecto a la cuestión de la responsabilidad del pueblo; nuestra perspectiva hace hincapié no tanto en el hecho de tener que rendir cuentas como en la responsabilidad de asumir el hecho de tomar decisiones. 
nar sobre un tema, considerarlo seriamente, meditarlo bien, pensarlo en profundidad, con el objeto de tomar una decisión. Este verbo es uno de los usados habitualmente para dar cuenta de la manera en que los oradores y el público interactuaban en la configuración de un pensamiento en una reunión asamblearia. Así sucede, nada más por citar dos ejemplos en los que la práctica de la asamblea aparece en un plano destacado, en Tucídides ${ }^{59}$ que usa el verbo dieciocho veces en el contexto de discursos públicos, generalmente en asambleas, y en Demóstenes,${ }^{60}$ que emplea el término más de sesenta veces en el conjunto de discursos que se le atribuyen.

Tampoco resulta casual que la configuración de este pensamiento de la toma de una decisión en asamblea se construya a partir de év $\theta v \mu o u ́ \mu \varepsilon \theta \alpha$, si tomamos en cuenta que en el uso de este verbo está connotado una palabra de la misma raíz, el èv $\theta u ́ \mu \eta \mu \alpha$, al que Aristóteles en la Retórica definía

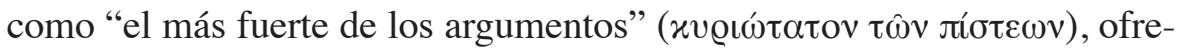
ciendo una delimitación de su campo de acción: se trata de un silogismo retórico que versa sobre lo verosímil o probable (عixós), es decir, una argumentación cuyas premisas son verosímiles o probables (Eixó $\alpha \alpha)$ y cuya finalidad no es la demostración lógica sino la persuasión. Ciertamente, los argumentos persuasivos son una especie de demostración retórica y esto es el entimema. ${ }^{61}$ Aristóteles sugería además la existencia de entimemas

${ }^{59}$ Th., I, 42, 1; I, 120, 5; I, 122, 2; II, 40, 2; II, 43, 1; III, 40, 5; V, 111, 2; V, 111, 5; VI, 60, 1; VI, 78, 1; VII, 63, 3; VII, 64, 2; VIII, 68, 1.

${ }^{60}$ D., Olynthiaca 1 (I), 6, 1, 21; Philippica 1 (IV), 3, 31, 32, 43; Philippica 3 (IX), 53; De Rhodiorum libertate (XV), 16, 35; Pro Megalopolitanis (XVI), 30; De corona (XVIII), 184; De falsa legatione (XIX), 1, 39, 239, 310; Adversus Leptinem (XX), 8, 118; In Midiam (XXI), 8, 11, 54, 197, 209; Adversus Androtionem (XXII), 43, 46; In Aristocratem (XXIII), 160, 162, 177; In Timocratem (XXIV), 28, 80, 138; In Aristogitonem 2 (XXVI), 18, 23; In Aphobum 2 (XXVIII), 17, 24; Contra Apatourium (XXXIII), 29; Contra Phormionem (XXXIV), 45; Contra Lacritum (XXXV), 35; Contra Pantaenetum (XXXVII), 43; Contra Boeotum 2 (XL), 22, 23, 26, 39, 47, 48, 50, 61; Contra Macartatum (XLIII), 60, 72; Contra Leocharem (XLIV), 4; In Stephanum 1 (XLV), 25, 28, 44; In Stephanum 2 (XLVI), 15, 28; In Evergum et Mnesibulum (XLVII), 33; In Olympiodorum (XLVIII), 9; Contra Polyclem (L), 66; Contra Nicostratum (LIII), 29; Contra Eubulidem (LVII), 3, 56, 57; In Neaeram (LIX), 115, 116; Eroticus (LXI), 4, 37. En nada disminuye el valor de este testimonio el hecho de que varios discursos atribuidos a Demóstenes se consideren espurios, pues el uso en ellos del verbo év $\theta v \mu \varepsilon ́$ o $\mu \alpha \iota$ sigue mostrando su importancia para la construcción de un argumento persuasivo en el marco de una pieza oratoria.

${ }^{61}$ Arist., Rh., 1355a 4-9; 1357a 23-33; 1396a 2-3. Cf. Cortés Gabaudan 1994; Iglesias Zoido 1997. Cf. Arnhart 1981, pp. 8-10; Kennedy 1996, pp. 173-174. Sobre el entimema, Barthes 1970, pp. 201-206. 
aparentes en la medida en que no serían absolutamente probables sino con respecto a algo, contexto en el que incluía la posibilidad de que un argumento en posición inicial débil pudiera transformarse en uno fuerte. ${ }^{62}$

Esta potencialidad en virtud de la cual un argumento verosímil o probable podía devenir en razonamiento fuerte nos conduce claramente al terreno de la convención, en tanto que, como planteaba Protágoras en el Teeteto de Platón (166d-167c), lo conveniente para la colectividad es lo que ella considere como tal, bajo un modo determinado mientras perdure

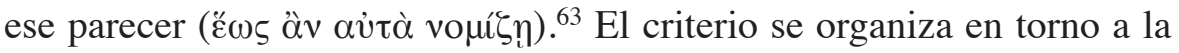
capacidad de pensar lo más conveniente para una comunidad, según las circunstancias y los criterios vigentes, y éste es el contexto en el que

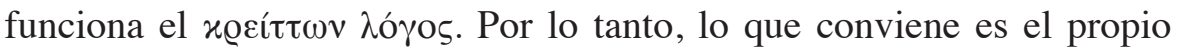
sustento de la cohesión social, y como tal implica un imaginario basado en representaciones aceptadas por la colectividad a partir de la función retórica del lenguaje. El lazo imaginario que hace ser a la comunidad es plenamente una ficción discursiva que se instituye según el devenir de las convenciones socialmente aceptadas. ${ }^{64}$ De modo que hay un parecer

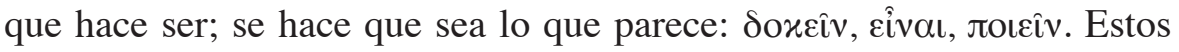
tres verbos, que en la apología de Protágoras aparecen conjuntamente en ese orden, muestran cuáles son los ejes de la doctrina sofista. Se trata en primer término de una práctica, pero también de una ontología relativa que no se liga al ser como una verdad fija e inmutable, sino al parecer cambiante de una colectividad: "Pues lo que a cada ciudad le parezca bueno y justo para ella, lo es mientras se mantenga en tal opinión". ${ }^{65}$ Así, el parecer conlleva adentrarse en el terreno de unas prácticas colectivas en las que resulta central el uso persuasivo del lenguaje que conduce a la conformación de un imaginario social. El parecer es lo que efectivamente es para una comunidad que toma eso como ley, norma o costumbre. El parecer cobra existencia a partir del trabajo retórico y persuasivo sobre el lenguaje. En un campo de fuerzas así concebido, el procedimiento diseñado implica una manera eficaz de construcción de lo verosímil que

${ }^{62}$ Arist., Rh., 1402a 7-9, 23-24. Cf. Solana Dueso 2000, pp. 173-178; Corradi 2013.

${ }^{63}$ Cf. Gallego 2003, pp. 333-334, 360-364.

${ }^{64}$ Detienne y Vernant 1974, p. 292.

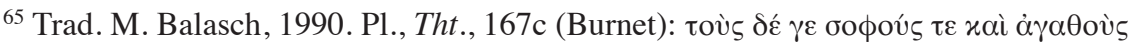

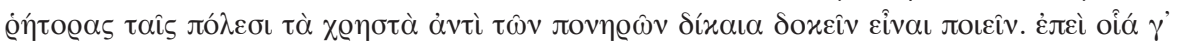

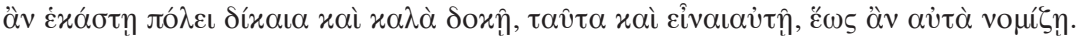


se sostiene como convención o acuerdo político: el lapso durante el cual una idea se mantiene instituida como socialmente válida es el tiempo de vigencia de un pensamiento confeccionado según los criterios de la verosimilitud..$^{66}$

Tal era la concepción sofística de la verdad, para la que el mundo resultaba una creación del $\log o s,{ }^{67}$ idea que Tucídides hacía decir, primero, a Pericles, cuando asumía que la palabra no era un perjuicio para la acción, sino precisamente lo contrario, y, después, a Diódoto, cuando criticaba a Cleón por negar la importancia de la palabra como guía para la acción. ${ }^{68}$ Pero henos aquí que al considerar la manera en que mediante el $\log o s$ se arribaba a decisiones políticas, el verbo $\dot{v} \theta v \mu o v ́ \mu \varepsilon \theta \alpha$ era invocado en boca de Pericles para dar cuenta del modo en que se configuraba un pensamiento de carácter colectivo en el marco del procedimiento asambleario. Su relación con un dispositivo de pensamiento en torno a lo verosímil sobre la base de la persuasión ya se ha indicado; también se ha dicho que ese pensamiento se organizaba mediante la palabra. Lo que ahora queremos destacar es que este uso de $\dot{\varepsilon} v \theta v \mu o v ́ \mu \varepsilon \theta \alpha$ en conjunción con logos parece implicar un límite para lo que este último puede tener de criterio puramente racional. Un verbo que denota pensamiento, pero

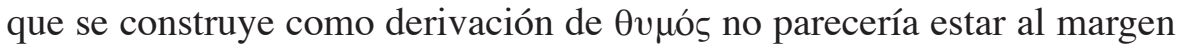
de algunos de los sentidos comprendidos en este término: desde alma, corazón o espíritu como principio de vida, pasando por temperamento, valor o coraje, e incluso cólera o ira, hasta llegar al sentido general de pasión o afecto. ${ }^{69}$

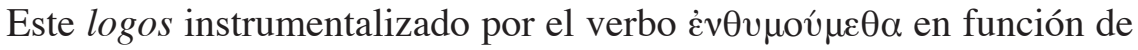
los asuntos o las acciones que verosímilmente pueden realizarse no es ya el imperio exclusivo de la razón al servicio de la contemplación de una verdad inmutable, cuyo precio sería retirarse del mundo para observarlo

${ }^{66}$ En su análisis del Protágoras, Demont 2013 examina el pasaje del Teeteto relacionándolo con la Colección hipocrática en lo atinente a la comparación entre el médico y el sofista para apoyar la idea central de su interpretación sobre la eficacia de la política para cambiar la situación de una ciudad, reconociendo que para Protágoras en cada ciudad rige el respeto y la justicia en relación con la ley, que por ningún motivo deja de ser una convención que, como tal, puede ser transformada. Cf. Cassin 1995, pp. 25, 111, 399; Zilioli 2007, pp. 62-64, 90-92.

${ }^{67}$ Cassin 1995, p. 73.

68 Th., II, 40, 2; III, 42, 2.

${ }^{69}$ Cf. Chantraine 1968-1980, s. v. Ovuós. Cf. Vernant 1989, p. 10, n. 8. 
en trascendencia. Los atenienses, a quienes se aplica en la "Oración fúnebre" de Pericles el verbo غ̇v $\theta v \mu o u ́ \mu \varepsilon \theta \alpha$ para resaltar su capacidad para pensar los asuntos políticos, aun cuando también puedan ser descritos como $\theta \varepsilon \alpha \tau \alpha \grave{~} \tau \hat{\omega} v \lambda$ ó $\gamma \omega v$, no observan el mundo desde una atalaya, sino que, en la inmanencia de la práctica política, consideran situacionalmente cómo hacer advenir un hecho como efecto de la palabra sometida a debate. La presencia del $\theta v \mu$ ós en el proceso de pensamiento de la decisión asamblearia habilita la dimensión de lo emocional en el terreno de la política, cuestión que, como advierte Barbara Koziak, ha quedado generalmente fuera de las explicaciones racionalistas de la comunidad política ${ }^{70}$ La formulación de una teoría de las emociones políticas implica que las configuraciones políticas no se explican con arreglo a visiones puramente racionales, sino que deben considerarse asimismo los factores pasionales o afectivos, lo cual apunta a replantear el problema desde un punto de vista que, aunque de otro modo, también ha sido puesto de relieve por Paul Ludwig. ${ }^{71}$

En la asamblea, el carácter emocional de la palabra política se organizaba en torno al $\theta v \mu o ́ s$, bajo los auspicios de غ̇v $\theta v \mu o u ́ \mu \varepsilon \theta \alpha$ como verbo del pensamiento de la acción, sobre la base del coraje, pero también de la

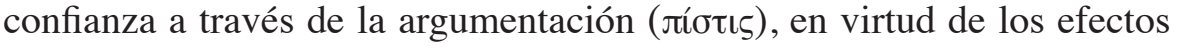
que la demostración retórica del entimema inducía en el auditorio a partir de la persuasión. Si en plena vigencia de la democracia de la época de Pericles estas condiciones eran las que aseguraban precisamente que el procedimiento tuviera capacidad de producir un "nosotros", como modo de pensamiento colectivo en pos de actuar en las situaciones y producir hechos con palabras, en la crisis de la democracia ateniense en 411 a. C., con el golpe oligárquico de los Cuatrocientos, sería la pérdida del coraje y la confianza, incluso su negación, lo que imposibilitaría que los ciudadanos en asamblea continuaran operando como aquellos

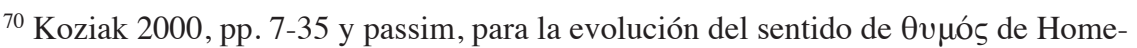
ro a Aristóteles. Cf. Lindsay 2000; Harris 2001, pp. 157-201; 2003, pp. 123-138; Cairns 2003, pp. 21-24; Faraone 2003; Viano 2003.

${ }^{71}$ Ludwig 2002, pp. 192-212; 2009, pp. 298-303. 


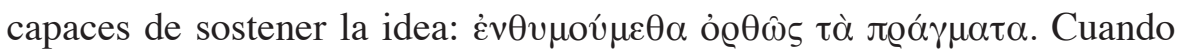
el miedo se adueñó de la condición subjetiva del pueblo, el coraje hubo de desaparecer, y con él la capacidad de pensamiento y decisión de la práctica asamblearia. Otra vez, Tucídides (VIII, 66, 2-5) nos ilustra sobre el dispositivo asambleario, en este caso para mostrar las condiciones de su destitución: ${ }^{72}$

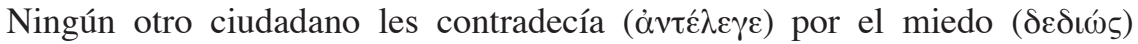
que les daba ver que los conjurados eran muchos. Y si alguien se oponía, al punto moría mediante algún cómodo expediente, sin que se buscara a los culpables ni se persiguiera judicialmente a los sospechosos, sino que los del pueblo permanecían sin reaccionar ( $\left.\eta_{\sigma} \sigma \chi i ́ \alpha v\right)$ y experimentaban tal terror ( $\alpha \alpha \tau \alpha ́ \tau \lambda \eta \xi เ v)$ que se consideraban afortunados si (aun permaneciendo en

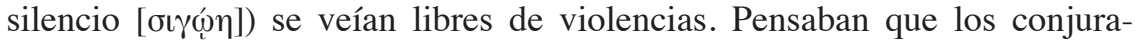
dos eran más de los que en realidad eran, y por ello se sentían desanima-

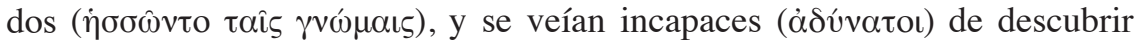
esto dada la enorme magnitud de la ciudad y el grado de desconocimiento (à $\gamma v \omega \sigma i ́ \alpha v)$ recíproco entre los ciudadanos. [...] Efectivamente, [alguien del pueblo] habría encontrado que a quien le iba a informar era o un desconocido

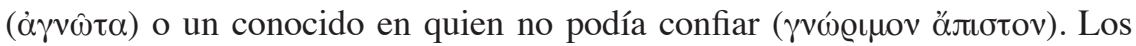
del pueblo se trataban en medio de continuos recelos, como si el interlocutor fuera un miembro activo de cuanto sucedía. En efecto, había personas de quienes nunca se habría pensado que se hubieran puesto del lado de la oligarquía; fueron éstos precisamente los que generaron mayor desconfianza

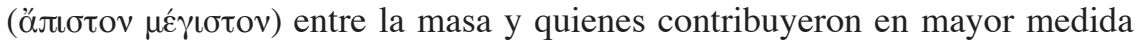
al éxito de los oligarcas, ya que reafirmaron en el pueblo su estado de desconfianza recíproca (

72 Sobre las implicaciones de este pasaje, ver Price 2001, pp. 308-310; Greenwood 2006, pp. 94-96; Zumbrunnen 2008, pp. 38-39; Taylor 2010, pp. 211-214; Shear 2011, pp. 29-31; Saïd 2013, p. 220.

73 Trad. de Guzmán Guerra, 1989 [modificada]. Th., VIII, 66, 2-5 (Jones y Powell):

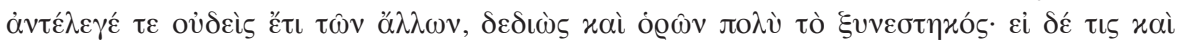

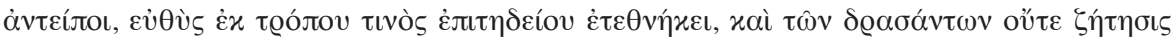

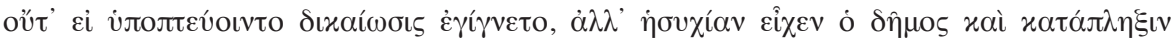

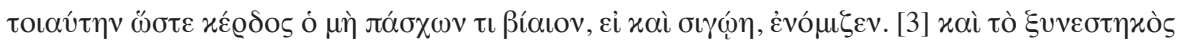

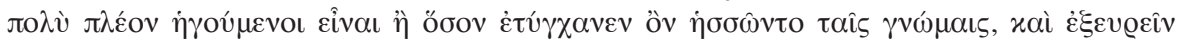

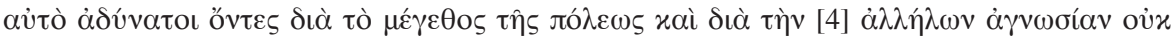

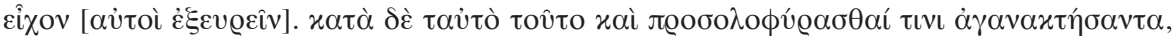

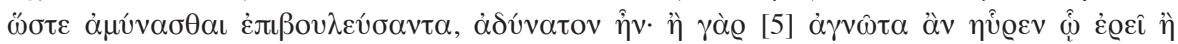

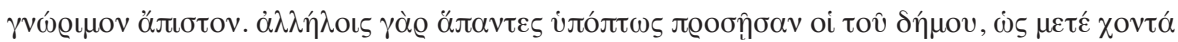

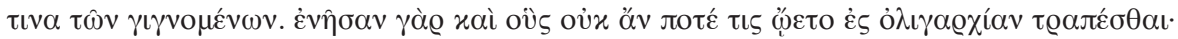


En un primer plano evidente, para Tucídides la incapacidad del pueblo cuando se produce el golpe oligárquico de 411 radica en la parálisis

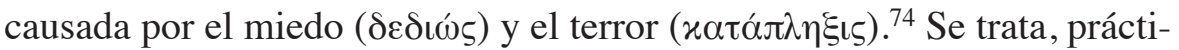
camente, de una ajustada inversión de los términos utilizados por Platón en el pasaje de las Leyes (701a-b) anteriormente citado, según el cual la subjetivación política del pueblo se produjo cuando perdió el miedo (äфoßos) y adquirió el poder efectivo de ocuparse por sí mismo de las

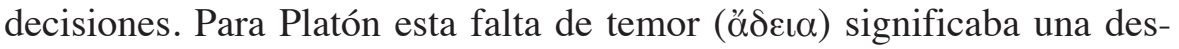
autorización de la aristocracia, ${ }^{75}$ una desobediencia que se manifestaba en el hecho de que la multitud ya no sentía miedo ( $\mu$ ì $\phi о \beta \varepsilon i ̂ \theta \alpha \iota)$ ante aquellos a quienes el filósofo consideraba como los más aptos para el gobierno. Sin miedo y sin temor implican la potencia de hacer política desembarazándose de la tutela de la élite, que supuestamente estaría por naturaleza destinada al mando. La libertad se contrapone al miedo, pues, como se deduce del argumento del Viejo Oligarca, si la élite pudiera castigar al pueblo, de modo de infundirle miedo y respeto ante su poder, entonces sería más fácil esclavizarlo. ${ }^{76}$ Es este miedo al poder de la élite oligárquica el que en 411 se instala como condición subjetiva del pueblo, una destitución de la capacidad política para la toma de decisiones que hasta ese momento detentaba.

Al contrastar el pasaje de Tucídides recién citado con el que aparecía en boca de Pericles en la "Oración fúnebre" se pone de relieve con-

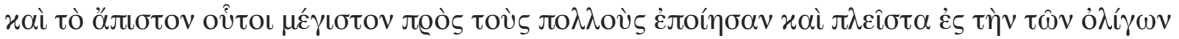

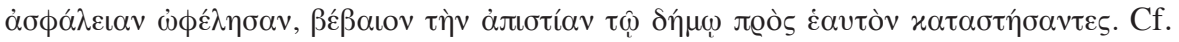
Hornblower 2008, pp. 944-949.

74 Tucídides ya había señalado previamente la cuestión de la confianza (Th., VIII, $54,1)$, que el pasaje citado desarrolla con mayor detalle: a pesar de su rechazo inicial a la proposición, el pueblo en asamblea aceptó instaurar una oligarquía, a causa del miedo

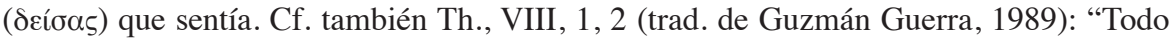
tipo de pesar, por todas partes les abrumaba y después de lo que había ocurrido, [los atenienses] sentían un miedo y una consternación mayor que nunca" ([Jones y Powell]

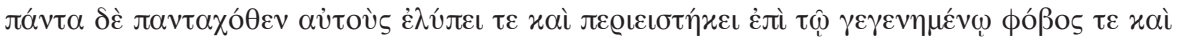

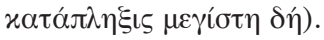

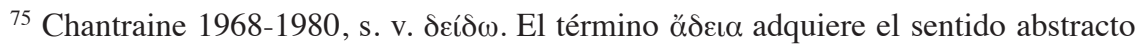
de "seguridad", de donde se llega a la idea de "autorización". La raíz dí $\omega$ presente en el verbo $\delta \varepsilon i ́ \delta \omega$ tiene el mismo sentido de "poner en fuga" que el verbo $\phi о \beta \varepsilon ́ \omega$, de donde procede por derivación la idea de "sentir o tener miedo". Cf. Liddell y Scott 1996, s.

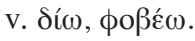

${ }^{76}$ [X.], Ath., I, 9; cf. Gallego 2012. 
ceptualmente la inversión operada en términos políticos y emocionales, vale decir, subjetivos, entre el coraje (

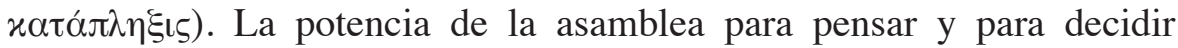
que hemos postulado como elemento relevante instituido por el verbo $\dot{\varepsilon} v \theta v \mu o v ́ \mu \varepsilon \theta \alpha$ queda depuesta en el momento en que, frente al accionar

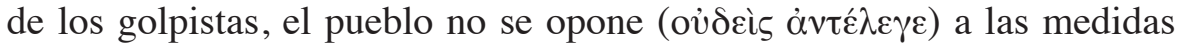
que quebrantan su poder. Esta defección es al mismo tiempo la destitu-

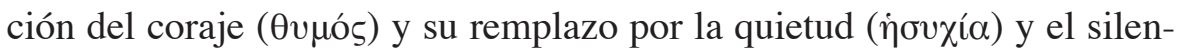

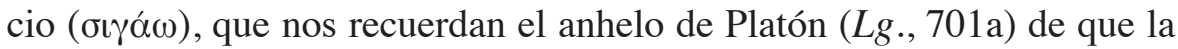

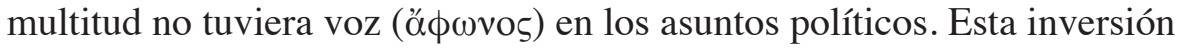
se verifica también en la aptitud para pensar las decisiones políticas en la medida en que, con el golpe oligárquico en marcha, los miembros

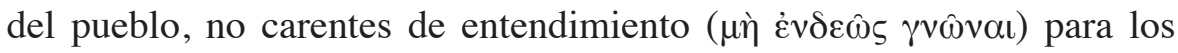
asuntos políticos conforme a la consideración de Pericles, comenzaron a sentirse incapacitados para reflexionar ( situación, de modo que el entendimiento parece haberse trocado en ignorancia ( $\dot{\alpha} \gamma \nu \omega \sigma i ́ \alpha)$. Si el entimema retórico, como instrumento del argumento persuasivo que infunde confianza ( $\pi i ́ \sigma \tau \iota \varsigma)$, está en la base del pensamiento práctico mediante el uso de la palabra para la toma de una

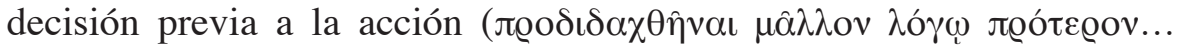

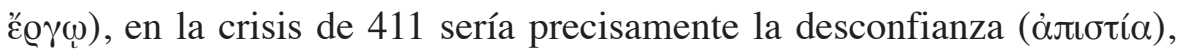
el sentirse incapaces (ảdúvatoı) de pensar colectivamente, lo que caracterizaría la relación subjetiva entre sí de los integrantes del pueblo.

De manera que de una situación en la que el pensamiento asambleario

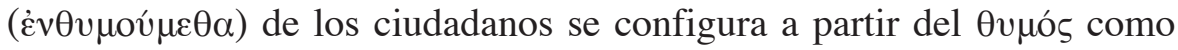
condición del pensar-actuar, llegamos a una situación en la que la comunidad en asamblea se disuelve, incapacitada para usar la palabra y responder debido a que el miedo, la parálisis y el terror han substituido al coraje democrático. Si la actividad instituyente de la asamblea supone que todos posean el entendimiento suficiente para aprender de antemano mediante la palabra, la destitución de la capacidad de pensamiento colectivo lleva precisamente a un desconocimiento recíproco, una ignorancia que produce tal dispersión de la comunidad que cada ciudadano pasa a ser un desconocido, o, lo que es lo mismo, un conocido no confiable. Los recelos y las sospechas entre unos y otros, sin rastros del "nosotros", conducen a la mayor desconfianza, señal de que el uso persuasivo de la palabra, sobre la base del entimema y la convicción que es capaz de generar, ha dejado de ser el modo mediante el cual se configura la comu- 
nidad en el acto político de pensar. La instauración y la extenuación de la confianza en el procedimiento asambleario permiten entender hasta qué punto los atenienses habían hecho de la asamblea un dispositivo de cohesión, un espacio de subjetivación política, cuya capacidad de producir un "nosotros" implicaba al mismo tiempo la configuración de dicho espacio como modo de habitarlo en la misma medida en que se pensaba colectivamente qué hacer. Cuando la asamblea cesa en su existencia, se queda sin palabra, pues deja de habitar en el coraje de producir pensamiento en acto.

\section{VI}

Las condiciones específicas de los espectadores en la democracia ateniense implicaban la facultad de decidir e interactuar con respecto al desarrollo del espectáculo, del que formaban parte no como meros receptores pasivos, sino como agentes activos de su concreción. En este contexto, la metáfora teatral utilizada por Cleón al calificar a los atenienses reunidos en la asamblea de "espectadores de discursos" y "oyentes de los hechos" termina revelando que, en realidad, se trata de una crítica no a la pasividad de los ciudadanos ante el uso persuasivo de la palabra por parte de los oradores, sino a la magnitud de la fuerza y la capacidad decisoria del pueblo reunido en asamblea. La articulación entre espacio político y escena teatral no es circunstancial, sino consustancial, pues, como demuestra Noémie Villacèque, en la Atenas democrática se opera una teatralización de la política y una politización del teatro. Buena prueba de ello es la asociación que el ateniense de las Leyes establece entre teatrocracia y democracia, a partir de la pérdida del miedo a la supuesta autoridad y superioridad natural de la aristocracia, una osadía ( ó$_{\lambda \mu \alpha}$ ) que se manifiesta como griterío y deliberación de la multitud.

La decisión del pueblo en asamblea se corresponde con estas características que Platón describía peyorativamente, sí, pero sin dejar de resaltar el carácter activo de la subjetivación política de la multitud. Para Pericles, esto comprendía el pensamiento bajo condiciones colectivas, asamblearias, donde el discurso persuasivo era palabra performativa, un decir que es un hacer. Era ese pensamiento, como deliberación y decisión para la acción, lo que constituía el coraje singular del pueblo ateniense, que en las reuniones de la asamblea producía un parecer polí- 
tico de la comunidad, ciertamente contingente, apelando no a los saberes técnicos de unos pocos, sino a la participación igualitaria de todos los ciudadanos, como se desprende de la perspectiva del Protágoras platónico. El pensamiento en asamblea, que el verbo żv $\theta v \mu o v ́ \mu \varepsilon \theta \alpha$ sintetiza al poner de relieve su relación intrínseca con el entimema y la idea de $\theta v \mu o ́ s$, muestra el carácter a un tiempo racional y pasional del uso de la palabra performativa, abriendo la política a la dimensión emocional, vale decir subjetiva, de la deliberación colectiva. La crisis desatada por el golpe oligárquico de 411 a. C. pone de relieve este conjunto de condiciones ligado a la subjetivación política del pueblo en el momento en que queda desinvestida: el coraje se trueca en miedo, el griterío en silencio, la actividad en quietud, la confianza en desconfianza, el pensamiento colectivo de la decisión en dispersión y desconocimiento sin capacidad de reflexión. El pueblo devino, entonces sí, en espectador pasivo de una escena política de la que se vio expulsado, perdiendo el poder de decisión que había sido el vector de su subjetivación.

\section{FUENTES Y BIBLIOGRAFÍA}

\section{Ediciones consultadas}

Aristophane, Comédies, ed. V. Coulon, trad. H. van Daele, Paris, Les Belles Lettres, 1923-1930 (Collection des Universités de France), 5 vols.

Aristotelis Ars Rhetorica, ed. W. D. Ross, Oxford, Clarendon Press, 1959 (Oxford Classical Texts).

- Ethica Eudemia, ed. F. Susemihl, Leipzig, Teubner Verlag, 1884 (Bibliotheca Teubneriana).

- Ethica Nicomachea, ed. I. Bywater, Oxford, Clarendon Press, 1894 (Oxford Classical Texts).

- Politics, ed. W. D. Ross, Oxford, Clarendon Press, 1957 (Oxford Classical Texts).

Aristotle, Poetics, Editio Maior of the Greek Text with Historical Introductions and Philological Commentaries, ed. L. Tarán y D. Gutas, Leiden, Brill, 2012 (Mnemosyne Supplements. Monographs on Greek and Latin Language and Literature).

M. Tullius Cicero, Tusculanae Disputationes, ed. M. Pohlenz, Leipzig, Teubner Verlag, 1918 (Bibliotheca Teubneriana).

Demosthenis Orationes, vols. I-II/1, ed. S. H. Butcher, Oxford, Clarendon Press, 1903-1907 (Oxford Classical Texts). 
- Orationes, vols. II/2-III, ed. W. Rennie, Oxford, Clarendon Press, 1921-1931 (Oxford Classical Texts).

Diogenis Laertil Vitae Philosophorum, ed. H. S. Long, Oxford, Clarendon Press, 1964 (Oxford Classical Texts), 2 vols.

FlaviI Philostrati Opera, vol. I (Vita Apollonii), ed. C. L. Kayser, Leipzig, Teubner Verlag, 1870 (Bibliotheca Teubneriana).

Hérodote, Histoires, ed. y trad. Ph. E. Legrand, Paris, Les Belles Lettres, 19321954 (Collection des Universités de France), 9 vols.

Iamblichus, De vita Pythagorica liber, ed. U. Klein y L. Deubner, Stuttgart, Teubner Verlag, 1975 [2 $2^{\mathrm{a}}$ ed.] (Bibliotheca Teubneriana).

Platonis Opera, vol. I (Theaetetus), ed. J. Burnet, Oxford, Clarendon Press, 1900 (Oxford Classical Texts).

- Opera, vol. III (Protagoras), ed. J. Burnet, Oxford, Clarendon Press, 1903 (Oxford Classical Texts).

- Opera, vol. IV (Respublica), ed. J. Burnet, Oxford, Clarendon Press, 1902 (Oxford Classical Texts).

- Opera, vol. V (Leges), ed. J. Burnet, Oxford, Clarendon Press, 1907 (Oxford Classical Texts).

Pollucis Onomasticon, ed. E. Bethe, Leipzig, Teubner Verlag, 1900-1931 (Bibliotheca Teubneriana), 2 vols.

Thucydidis Historiae, ed. H. S. Jones y J. E. Powell, Oxford, Clarendon Press, 1942 (Oxford Classical Texts), 2 vols.

Xenophontis Opera Omnia, vol. V (Atheniensium respublica [Sp.]), ed. E. C. Marchant, Oxford, Clarendon Press, 1920 (Oxford Classical Texts).

\section{Traducciones utilizadas}

Aristófanes, Comedias, trad. L. M. Macía Aparicio, Madrid, Ediciones Clásicas, 2009 (Colección de Autores Griegos), 3 vols.

ARISTÓTEles, Ética a Nicómaco, ed. y trad. M. Araujo y J. Marías, Madrid, Instituto de Estudios Políticos, 1959 (Colección Clásicos Políticos).

-, Ética Eudemia, trad. A. Gómez Robledo, México, Universidad Nacional Autónoma de México, 1994 (Bibliotheca Scriptorum Graecorum et Romanorum Mexicana).

_, Poética, trad. E. Sinnott, Buenos Aires, Ediciones Colihue, 2009 (Colihue Clásica).

—, Política, trad. P. López Barja de Quiroga y E. García Fernández, Madrid Ediciones Istmo, 2005 (Colección Fundamentos. Serie Clásicos del Pensamiento Político).

—, Retórica, ed. y trad. A. Tovar, Madrid, Instituto de Estudios Políticos, 1953 (Colección Clásicos Políticos).

Cicerón, Disputaciones Tusculanas, trad. A. Medina González, Madrid, Editorial Gredos, 2005 (Biblioteca Clásica Gredos). 
Diógenes LAercio, Vidas y opiniones de los filósofos ilustres, trad. C. García Gual, Madrid, Alianza Editorial, 2007 (El Libro de Bolsillo).

Filóstrato, Vida de Apolonio de Tiana, trad. A. Bernabé Pajares, Madrid, Editorial Gredos, 1979 (Biblioteca Clásica Gredos).

Heródoto, Historia, trad. C. Schrader, Madrid, Editorial Gredos, 1977-1989 (Biblioteca Clásica Gredos), 5 vols.

Jámblico, Vida Pitagórica . Protréptico, trad. M. Periago Lorente, Madrid, Editorial Gredos, 2003 (Biblioteca Clásica Gredos).

Platón, Diálogos I (Protágoras), trad. J. Calonge Ruiz, E. Lledó Iñigo y C. García Gual, Madrid, Editorial Gredos, 1981 (Biblioteca Clásica Gredos).

—, Diálogos IV (República), trad. C. Eggers Lan, Madrid, Editorial Gredos, 1986 (Biblioteca Clásica Gredos).

—, Las Leyes, ed. y trad. J. M. Pabón y M. Fernández-Galiano, Madrid, Instituto de Estudios Políticos, 1960 (Colección Clásicos Políticos), 2 vols.

-, Teeteto, ed. y trad. M. Balasch, Barcelona, Anthropos Editorial del Hombre, 1990 (Textos y Documentos).

Pseudo-Jenofonte, La República de los Atenienses, ed. y trad. M. FernándezGaliano, Madrid, Instituto de Estudios Políticos, 1951 (Colección Clásicos Políticos).

Tucídides, Historia de la guerra del Peloponeso, trad. A. Guzmán Guerra, Madrid, Alianza Editorial, 1989 (El Libro de Bolsillo).

\section{Instrumenta}

Chantraine, Pierre, Dictionnaire étymologique de la langue grecque, Paris, Éditions Klincksieck, 1968-1980.

Liddell, Henry G., y Robert ScOTT, Greek-English Lexicon, with a Revised Supplement [H. S. Jones], Oxford, Clarendon Press, 1996.

\section{Bibliografía}

Andrews, James, “Cleon's Hidden Appeals (Thucydides 3.37-40)”, CQ, 50, 2000, pp. 45-62.

Arendt, Hannah, The Human Condition, Chicago, University of Chicago Press, 1958.

-, The Life of the Mind. 1) Thinking, New York, Harcourt Brace Jovanovich, $1977^{2}$.

Arnhart, Larry, Aristotle on Political Reasoning. A Commentary on the Rhetoric, Illinois, Northern Illinois University Press, 1981.

Austin, John Langshaw, How to Do Things with Words, ed. J. O. Urmson, Oxford, Clarendon Press, 1962.

BAIN, David, "Audience Address in Greek Tragedy", $C Q, 25,1975$, pp. 13-25. 
BaLOT, Ryan, "Pericles' Anatomy of Democratic Courage", AJP, 122, 2001, pp. 505-525.

-, "Courage in the Democratic Polis", $c Q$, 54, 2004a, pp. 406-423.

-, "Free Speech, Courage, and Democratic Deliberation", en I. Sluiter y R. M. Rosen (eds.), Free Speech in Classical Antiquity, Leiden, Brill, 2004b, pp. 233259.

-, "Democratizing Courage in Classical Athens", en D. M. Pritchard (ed.), War, Democracy and Culture in Classical Athens, Cambridge, Cambridge University Press, 2010, pp. 88-108.

-, Courage in the Democratic Polis. Ideology and Critique in Classical Athens, Oxford, Oxford University Press, 2014.

BARTHES, Roland, "L'ancienne rhétorique. Aide-mémoire", Communications, 16, 1970, pp. 172-223.

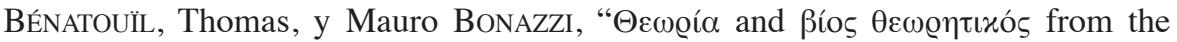
Presocratics to the End of Antiquity: An Overview", en T. Bénatouïl y M. Bonazzi (eds.), Theoria, Praxis, and the Contemplative Life after Plato and Aristotle, Leiden, Brill, 2012, pp. 1-14.

-, (eds.), Theoria, Praxis, and the Contemplative Life after Plato and Aristotle, Leiden, Brill, 2012.

Bers, Victor, "Dikastic Thorubos", en P. A. Cartledge y F. D. Harvey (eds.), Crux. Essays Presented to G. E. M. de Ste. Croix, London, Duckworth, 1985, pp. 1-15. Birmingham, Peg, "Hannah Arendt: The Spectator's Vision", en J. J. Hermsen y D. R. Villa (eds.), The Judge and the Spectator. Hannah Arendt's Political Philosophy, Leuven, Peeters, 1999, pp. 29-41.

CaIRns, Douglas, "Ethics, Ethology, Terminology: Iliadic Anger and the CrossCultural Study of Emotion", en S. Braund y G. W. Most (eds.), Ancient Anger. Perspectives from Homer to Galen, Cambridge, Cambridge University Press, 2003, pp. 11-49.

CAssin, Barbara, L'effet sophistique, Paris, Éditions Gallimard, 1995.

CoHEN, David, "Justice, Interest, and Political Deliberation in Thucydides", QUCC, n. s. 16, 1984, pp. 35-60.

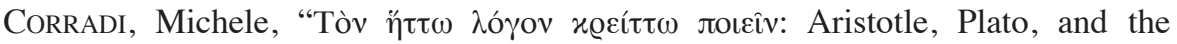
$\varepsilon \dot{\pi} \alpha \gamma_{\gamma} \varepsilon \lambda \mu \alpha$ of Protagoras", en J. M. van Ophuijsen, M. van Raalte y P. Stork (eds.), Protagoras of Abdera. The Man, his Measure, Leiden, Brill, 2013, pp. 69-86.

Cortés Gabaudan, Francisco, "Formas y funciones del entimema en la oratoria ática", Cuadernos de Filología Clásica, 4, 1994, pp. 205-225.

DAVIDSON, John, "Carcinus and the Temple: A Problem in the Athenian Theater", CPh, 98, 2003, pp. 109-122.

Demont, Paul, "L'efficacité en politique selon le Protagoras de Platon", en J. M. van Ophuijsen, M. van Raalte y P. Stork (eds.), Protagoras of Abdera. The Man, his Measure, Leiden, Brill, 2013, pp. 113-138.

Detienne, Marcel, y Jean-Pierre Vernant, Les ruses de l'intelligence. La mètis des Grecs, Paris, Éditions Flammarion, 1974. 
Dobrov, Gregory, Figures of Play. Greek Drama and Metafictional Poetics, Oxford, Oxford University Press, 2001.

EDMunds, Lowell, “Thucydides ii. 40. 2”, $C R$, n. s. 22, 1972, pp. 171-172.

FARAOnE, Christopher, "Thumos as Masculine Ideal and Social Pathology in Ancient Greek Magical Spells", en S. Braund y G. W. Most (eds.), Ancient Anger. Perspectives from Homer to Galen, Cambridge, Cambridge University Press, 2003, pp. 144-162.

Festugière, André, Contemplation et vie contemplative selon Platon, Paris, Éditions Vrin, 1936.

Gallego, Julián, La democracia en tiempos de tragedia. Asamblea ateniense y subjetividad política, Buenos Aires, Miño y Dávila / Universidad de Buenos Aires, 2003.

—, "La asamblea ateniense y el problema del Estado. Instauración y agotamiento de una subjetividad política", en M. Campagno, J. Gallego, C. G. García Mac Gaw (eds.), El Estado en el Mediterráneo antiguo. Egipto, Grecia, Roma, Buenos Aires, Miño y Dávila, 2011, pp. 181-222.

- , "Los poneroí y la crisis de la democracia radical ateniense. La propuesta del Viejo Oligarca sobre la esclavitud del dêmos", en F. Reduzzi (ed.), Dipendenza ed emarginazione nel Mondo Antico e Moderno, Roma, Aracne Editrice, 2012, pp. 89-101.

GARCÍA Romero, Fernando, "Sports Tourism in Ancient Greece”, Journal of Tourism History, 5, 2013, pp. 146-160.

GARVER, Eugene, "Aristotle on the Kinds of Rhetoric", Rhetorica, 27, 2009, pp. $1-18$.

GoldhiLl, Simon, "The Great Dionysia and Civic Ideology”, JHS, 107, 1987, pp. 58-76.

- , "The Audience of Athenian Tragedy", en P. E. Easterling (ed.), The Cambridge Companion to Greek Tragedy, Cambridge, Cambridge University Press, 1997, pp. 54-68.

- , "Programme Notes", en S. Goldhill y R. Osborne (eds.), Performance Culture and Athenian Democracy, Cambridge, Cambridge University Press, 1999, pp. $1-29$.

GreEn, J. Richard, "Carcinus and the Temple: A Lesson in the Staging of Tragedy", GRBS, 31, 1990, pp. 281-285.

GreEnwood, Emily, Thucydides and the Shaping of History, London, Duckworth, 2006.

Hallward, Peter, "Staging Equality: On Rancière's Theatrocracy", New Left Review, 37, 2006, pp. 109-129.

- , "Staging Equality: Rancière's Theatrocracy and the Limits of Anarchic Equality”, en G. Rockhill y Ph. Watts (eds.), Jacques Rancière. History, Politics, Aesthetics, Durham, Duke University Press, 2009, pp. 140-157.

HARris, Edward, "How to Address the Athenian Assembly: Rhetoric and Political Tactics in the Debate about Mytilene (Thuc. 3.37-50)", CQ, 63, 2013, pp. 94109. 
-, Restraining Rage. The Ideology of Anger Control in Classical Antiquity, Cambridge, Harvard University Press, 2001.

-, "The Rage of Women", en S. Braund y G. W. Most (eds.), Ancient Anger. Perspectives from Homer to Galen, Cambridge, Cambridge University Press, 2003, pp. 121-143.

Henderson, John, "The Demos and the Comic Competition", en J. J. Winkler y F. I. Zeitlin (eds.), Nothing to Do with Dionysos? Athenian Drama in its Social Context, Princeton, Princeton University Press, 1990, pp. 271-313.

Hesk, John, "The Rhetoric of Anti-Rhetoric in Athenian Oratory", en S. Goldhill y R. Osborne (eds.), Performance Culture and Athenian Democracy, Cambridge, Cambridge University Press, 1999, pp. 201-230.

-, Deception and Democracy in Classical Athens, Cambridge, Cambridge University Press, 2000.

-, “'Despisers of the Commonplace': Meta-topoi and Para-topoi in Attic Oratory", Rhetorica, 25, 2007, pp. 361-384.

Hornblower, Simon, A Commentary on Thucydides. Volume I: Books I-III, Oxford, Oxford University Press, 1991.

—, A Commentary on Thucydides. Volume III: Books 5.25-8.109, Oxford, Oxford University Press, 2008.

Hubbard, Thomas, The Mask of Comedy. Aristophanes and the Intertextual Parabasis, Ithaca, Cornell University Press, 1991.

IgLesias Zoido, Juan C., "Paradigma y entimema: el ejemplo histórico en los discursos deliberativos de Tucídides”, Emerita, 65, 1997, pp. 109-122.

JAEGER, Werner, Paideia. Los ideales de la cultura griega, trad. J. Xirau y W. Roces, México, Fondo de Cultura Económica, 1957 [1936-1947].

KenNeDy, George, "Reworking Aristotle's Rhetoric", en C. L. Johnstone (ed.), Theory, Text, Context. Issues in Greek Rhetoric and Oratory, Albany, State University of New York Press, 1996, pp. 169-184.

KozIAK, Barbara, Retrieving Political Emotion. Thumos, Aristotle, and Gender, Pennsylvania, Pennsylvania State University Press, 2000.

Landauer, Matthew, "Parrhesia and the Demos Tyrannos: Frank Speech, Flattery and Accountability in Democratic Athens", History of Political Thought, 33, 2012, pp. 185-208.

LANG, Mabel, "Cleon as the Anti-Pericles", $C P h, 67,1972$, pp. 159-169.

LinDSAY, Thomas, "Aristotle's Appraisal of Manly Spirit: Political and Philosophic Implications", American Journal of Political Science, 44, 2000, pp. 433-448.

LONGWORTH, Guy, "John Langshaw Austin", en E. N. Zalta (ed.), The Stanford Encyclopedia of Philosophy (Summer 2015 Edition), Stanford, Stanford University, 2015, http://plato.stanford.edu/archives/sum2015/entries/austin-jl/ [Consulta en línea: 17-09-2015].

Loraux, Nicole, Les mères en deuil, Paris, Éditions du Seuil, 1990.

-, L'Invention d'Athènes. Histoire de l'oraison funèbre dans la "cité classique", Paris, Éditions Payot, $1993^{2}$.

—, La cité divisée. L'oubli dans la mémoire d'Athènes, Paris, Éditions Payot, 1997. 
Loraux, Nicole, La voix endeuillée. Essai sur la tragédie grecque, Paris, Éditions Gallimard, 1999.

Ludwig, Paul, Eros and Polis. Desire and Community in Greek Political Theory, Cambridge, Cambridge University Press, 2002.

- " "Anger, Eros, and Other Political Passions in Ancient Greek Thought", en R. Balot (ed.), A Companion to Greek and Roman Political Thought, MaldenOxford, Wiley / Blackwell, 2009, pp. 294-307.

MAra, Gerald, The Civic Conversations of Thucydides and Plato. Classical Political Philosophy and the Limits of Democracy, Albany, State University of New York Press, 2008.

Marin, Louis, Des pouvoirs de l'image. Gloses, Paris, Éditions du Seuil, 1993.

Monoson, S. Sara, Plato's Democratic Entanglements. Athenian Politics and the Practice of Philosophy, Princeton, Princeton University Press, 2000.

NAGY, Gregory, "Transformations of Choral Lyric Traditions in the Context of Athenian State Theater", Arion, III/3, 1994/1995, pp. 41-55.

Nightingale, Andrea, Spectacles of Truth in Classical Greek Philosophy. Theoria in its Cultural Context, Cambridge, Cambridge University Press, 2004.

Ober, Josiah, Mass and Elite in Democratic Athens. Rhetoric, Ideology and the Power of the People, Princeton, Princeton University Press, 1989.

- , y Barry Strauss, "Drama, Political Rhetoric, and the Discourse of Athenian Democracy", en J. J. Winkler y F. I. Zeitlin (eds.), Nothing to Do with Dionysos? Athenian Drama in its Social Context, Princeton, Princeton University Press, 1990, pp. 237-270.

Orwin, Clifford, "Democracy and Distrust: A Lesson from Thucydides", American Scholar, 53, 1984, pp. 313-325.

PrICE, Jonathan, Thucydides and Internal War, Cambridge, Cambridge University Press, 2001.

RANCIÈRE, Jacques, El filósofo y sus pobres, trad. M. Bardet y N. Goldwaser, Los Polvorines, Universidad Nacional de General Sarmiento, 2013 [2002].

ReHM, Rush, The Play of Space. Spatial Transformation of Greek Tragedy, Princeton, Princeton University Press, 2002.

Revermann, Martin, "The Competence of Theatre Audiences in Fifth- and FourthCentury Athens", JHS, 126, 2006, pp. 99-124.

Roselli, David, Theater of the People. Spectators and Society in Ancient Athens, Austin, University of Texas Press, 2011.

Rocco, Christopher, Tragedy and Enlightenment. Athenian Political Thought and the Dilemmas of Modernity, Berkeley, University of California Press, 1997.

Rusten, Jeffrey, "Two Lives or Three? Pericles on the Athenian Character (Thucydides 2.40.1-2)", $C Q, 35,1985$, pp. 14-19.

Saetta Cottone, Rossella, "Injures onomasti et public: éléments pour une analyse interactionnelle”, La comédie d'Aristophane et son public. Methodos. Savoirs et Textes, 7, 2007, http://methodos.revues.org/611 [Consulta en línea: 17-092015]. 
SAÏD, Suzanne, "Thucydides and the Masses", en A. Tsakmakis y M. Tamiolaki (eds.), Thucydides between History and Literature, Berlin, Walter de Gruyter, 2013, pp. 199-224.

SHEAR, Julia, Polis and Revolution. Responding to Oligarchy in Classical Athens, Cambridge, Cambridge University Press, 2011.

SLATER, Niall, "Making the Aristophanic Audience", AJPh, 120, 1999, pp. 351368.

-, Spectator Politics. Metatheatre and Performance in Aristophanes, Philadelphia, University of Pennsylvania Press, 2002.

Solana Dueso, José, El camino del ágora. Filosofía política de Protágoras de Abdera, Zaragoza, Universidad de Zaragoza, 2000.

Strauss, Barry, Fathers and Sons in Athens. Ideology and Society in the Era of the Peloponnesian War, London, Routledge, 1993.

TACON, Judith, "Ecclesiastic Thorubos: Interventions, Interruptions, and Popular Involvement in the Athenian Assembly", $G \& R$, 48, 2001, pp. 173-192.

TAYLOR, Martha, Thucydides, Pericles, and the Idea of Athens in the Peloponnesian War, Cambridge, Cambridge University Press, 2010.

Tritle, Lawrence, "Thucydides and Power Politics", en A. Rengakos y A. Tsakmakis (eds.), Brill's Companion to Thucydides, Leiden, Brill, 2006, pp. 469491.

Vernant, Jean-Pierre, L'individu, la mort, l'amour, Paris, Éditons Gallimard, 1989.

VIANO, Cristina, "Competitive Emotions and Thumos in Aristotle's Rhetoric", en D. Konstan y N. K. Rutter (eds.), Envy, Spite and Jealousy. The Rivalrous Emotions in Ancient Greece, Edinburgh, Edinburgh University Press, 2003, pp. 85-97.

VillacÈQue, Noémie, "Ce que le peuple en dit. Le messager tragique et la démocratie", $Q S, 66,2007 \mathrm{a}$, pp. 81-117.

-, “' 'Toi, spectateur de mes tourments'. Les adresses au public dans la tragédie grecque", Cahiers Glotz, 18, 2007b, pp. 263-280.

-, Spectateurs de paroles! Délibération démocratique et théâtre à Athènes à l'époque classique, Rennes, Presses Universitaires de Rennes, $2013 \mathrm{a}$.

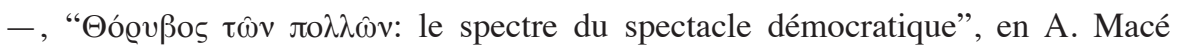
(ed.), Le savoir public. La vocation politique du savoir en Grèce ancienne, Besançon, Presses Universitaires de Franche-Comté, 2013b, pp. 287-312.

Wallace, Robert, "Poet, Public, and 'Theatrocracy': Audience Performance in Classical Athens", en L. Edmunds y R. W. Wallace (eds.), Poet, Public, and Performance in Ancient Greece, Baltimore, Johns Hopkins University Press, 1997, pp. 97-111.

Weber, Samuel, Theatricality as Medium, New York, Fordham University Press, 2004.

Wilson, Peter, The Athenian Institution of Khoregia. The Chorus, the City and the Stage, Cambridge, Cambridge University Press, 2000. 
Woodruff, Paul, "Euboulia as the Skill Protagoras Taught", en J. M. van Ophuijsen, M. van Raalte y P. Stork (eds.), Protagoras of Abdera. The Man, his Measure, Leiden, Brill, 2013, pp. 179-193.

WoHL, Victoria, Love among the Ruins. The Erotics of Democracy in Classical Athens, Princeton, Princeton University Press, 2002.

WRIGHT, Matthew, "Literary Prizes and Literary Criticism in Antiquity", ClAnt, 28, 2009, pp. 138-177.

Zilioli, Ugo, Protagoras and the Challenge of Relativism. Plato's Subtlest Enemy, Aldershot, Ashgate, 2007.

Zumbrunnen, John, "Democratic Politics and the 'Character' of the City in Thucydides", History of Political Thought, 23, 2002, pp. 565-589.

-, "Elite Domination and the Clever Citizen. Aristophanes' Acharnians and Knights", Political Theory, 32, 2004, pp. 656-677.

-, Silence and Democracy. Athenian Politics in Thucydides' History, Pennsylvania, Pennsylvania State University Press, 2008. 